\title{
Expanded Indications of Full Endoscopic Spine Sugery
}

\author{
Ajay Krishnan ${ }^{1}$, Hyeun Sung Kim², Aditya Raj ${ }^{3}$, Bharat R Dave ${ }^{1}$ \\ ${ }^{1}$ Department of Spine Surgery, ${ }^{3}$ Spine Fellow, Stavya Spine Hospital \& Research Institute, Nr Nagari Hospital, Mithakhali, Ellisbridge, \\ Ahmedabad, Gujarat, India \\ ²Department of Neurosurgery, Nanoori Gangnam Hospital, Seoul, Spine Surgery, Seoul, Republic of Korea
}

Corresponding Author: Ajay Krishnan, MS Departments of Spine Surgeon, C302, Orange Avenue, Maple County 1, Thaltej, Ahmedabad, Gujarat, India-380059

Tel: +91-98-2430-2768, Fax:

+91-79-2640-8174

Email: drajaykrishnan@gmail.com
Treatment of spine surgeries has evolved from traditional surgeries to open surgeries. Endoscopic spine surgeries (ESS) and endoscope assisted surgeries along with microscopic and tubular surgeries has developed significantly over the last three decades. With improvement in the diagnostic methods it is now possible to find and differentiate the spinal pathologies. ESS was initially limited to the lumbar disc herniations (DH). But, now it can be used for cervical and thoracic DH. Minimized technical problems has been brought by evolutions in endoscopy, better optics, instruments, access, and safety. Similarly acquired knowledge and skills are being extrapolated to advanced indications in different spinal pathologies. Due to the further advantages of ESS within the ambit of minimal invasive spine surgeries, many misnomers are as well getting added. This confuses the new learners and potential patients as well. ESS should be classified for uniformity in reporting and common nomenclature like FESS (Full endoscopic spine surgery) should be used. It specifically refers to surgery through one working channel under irrigation with incorporated optics. This will make easier understanding for novice surgeons and general population. It will lead to standardised reporting of high quality clinical studies, trials, and meta-analysis for the publications. Rising misnomers and complex nomenclature of endoscopy is suggesting along with the exponential publications in last decade that ESS is entering into its golden era. This review is undertaken to throw light on the techniques, advances and literature review of only FESS and clear the misnomers. This review also describes the evolution of different techniques and goals that led to impeccable advances in the field of FESS. Further improvement of technologies and techniques in future will soon establish FESS as the Gold Standard in spine surgery.

Key Words: Full Endoscopy, Spine, Surgery, Working Channel, Lumbar, Cervical, Thoracic, Sacral
Received: March 04, 2021

Revised: March 05, 2021

Accepted: March 07, 2021

\section{INTRODUCTION}

Patients have started demanding for the least invasive procedures for all spine surgeries and its equally evident with the training desires of the novice and accomplished spine surgeons. In the last quarter of the $20^{\text {th }}$ century and early $21^{\text {st }}$ century, there has been an evident shift from traditional open to minimal invasive spinal surgical techniques (MIS). Endoscopic Spine surgeries (ESS) are also a spectrum of this $\mathrm{MIS}^{1-4)}$. In the last ten years, there has been an exponential increase in ESS practice. It is evolving from individual spine surgeons practice to institutional practice and is getting better incorporated ${ }^{1,3,5-7)}$. Now even universities and spine societies are incorporating spine endoscopy in their curriculum and guidelines exemplified by North American Spine
Society (NASS).

There are numerous reasons for this development. In general, minimal incision reduces the extent of underlying tissue disruption and blood loss. This leads to cascading events of reduced tissue dissection and trauma leading to negligible disruption of structural and functional ability of spine. This further reduces postoperative pain and incidence of complications. Moreover it increases patient confidence, cosmesis, improved clinical outcomes with quality of life, early ambulation with return to work and reduced length of hospital stay ${ }^{1,3,5)}$.

Initially, ESS technique was restricted to the lumbar, cervical and thoracic disc herniations (DH). But gradually it has also found use for stenosis and ESS fusion ${ }^{3,5,8)}$. Although validating higher evidence is much needed to support the advanced ESS techniques and surgical indications, it now appears that the ESS is 
slowly entering into the mainstream arena, ${ }^{1,4)}$.

These improvements and advances happened on the shoulders of pioneers, and with concurrent improvements in the optics, high resolution camera, light source, cutting instruments, hand instruments, irrigation pump, navigation etc, and with better specific diagnosis and classification of the disorders ${ }^{3,9)}$.

During the initial practice, higher than normal rates of symptomatic recurrences and treatment failures should be anticipated by surgeons when incorporating ESS techniques ${ }^{4)}$. These are going to be even more with exciting extrapolation of the acquired ESS skills into new advanced indications.

The authors in this review article aim to describe the anatomical corridors, techniques for full ESS approaches to the cervical, thoracic and lumbo-sacral spine. The current full-endoscopic techniques advances to discuss the potential benefits, limitations, and future perspectives. Key relevant literature evidence respective to the techniques are also cited. These were identified from Google Scholar, PubMed and the Cochrane Library with cross- referencing of articles. Emphasis has been placed on literature published in the last ten years.

\section{History}

There are many misnomers or tantamount terms used in ESS. This creates a lot of confusion in the minds of beginner surgeons and patients. But, the most common and minimalistic surgical approach system in ESS is the full-endoscopic spine surgery (FESS). It is defined typically by: use of a working channel endoscope with the working channel, the optics and irrigation ingress/regress channel in the same device; complete uniportal percutaneous approach with a stab skin incision; and works with continuous saline irrigation ${ }^{37-43)}$. This has now become the standard ESS. Table 1 shows an overview of the current classification of endoscopic techniques.

Ahn's Classification of ESS is a simple explanation of the complex nomenclature of endoscopy ${ }^{5}$. International consensus paper on a unified nomenclature for FESS exists ${ }^{44)}$. We are suggesting further modifications in this AO Spine ESS Nomenclature System for easy understanding and comprehensiveness of this review.

Table 1. History

\begin{tabular}{|c|c|c|}
\hline Year & Pioneers & Invention \\
\hline 1909 & Krause \& Oppenheim ${ }^{10)}$ & First lumbar discectomy \\
\hline 1911 & Goldthwaite \& Middleton ${ }^{11)}$ & Described nucleus pulposus as the reason of the low back pain \\
\hline 1931 & Burman $^{12)}$ & Introduced the concept of Epiduroscopy \\
\hline 1931 & Leu $^{13)}$ & Reported the use of peridural intraductal endoscopies via the sacral approach technique \\
\hline 1934 & Mixter \& Barr ${ }^{14)}$ & $\begin{array}{l}\text { They actually published the first series of successful disc operations in 1934. Their } \\
\text { technique however was a complete laminectomy and some of the disc herniations were } \\
\text { removed through a trans-dural approach }\end{array}$ \\
\hline 1939 & Love $e^{15)}$ & Inter-laminar approach which became standard procedure for many years \\
\hline 1973 & Parviz Kambin ${ }^{16)}$ & Transforaminal access \\
\hline 1977 & Yasargil \& Caspar ${ }^{17,18)}$ & Microsurgical-Interlaminar approach \\
\hline 1978 & Tax williams ${ }^{19)}$ & First surgeon to implement the microsurgical-interlaminar approach in the United States \\
\hline 1983 & Forst \& Hausmann ${ }^{201}$ & $\begin{array}{l}\text { Introduces a modified endoscopic camera through the working cannula through which } \\
\text { they were able to examine the intervertebral disc. }\end{array}$ \\
\hline 1989 & Schreiber \& Suezawa ${ }^{21)}$ & $\begin{array}{l}\text { Began to perform nucleotomy under continuous endoscopic visualization, and reported } \\
\text { successful outcomes in } 72.5 \% \text { of patients who had a herniated lumbar disc }\end{array}$ \\
\hline 1997 & Yeung ${ }^{9)}$ & Yeung endoscopic spine system-Inside Out Approach \\
\hline 1998 & Thomas Hoogland ${ }^{9)}$ & Hoogland endoscopic system-Outside In approach \\
\hline 1999 & Foley \& Smith ${ }^{221}$ & $\begin{array}{l}\text { Reported their experience of micro-endoscopic discectomy for far-lateral disc herniation } \\
\text { in } 11 \text { consecutive patients using a tubular retractor and disposable endoscope. }\end{array}$ \\
\hline 2002 & Fessler \& $\mathrm{Khoo}^{23)}$ & $\begin{array}{l}\text { Applied these micro-endoscopic techniques to cervical foraminotomy in cadaveric } \\
\text { specimens and subsequently in clinical settings in } 2002 \text {. }\end{array}$ \\
\hline 2003 & S. Ruetten ${ }^{24)}$ & $\begin{array}{l}\text { Described the use of epiduroscopy guided interventions in patients of chronic back leg } \\
\text { pain syndromes in } 2003\end{array}$ \\
\hline 2005 & Schubert \& T.Hoogland ${ }^{25)}$ & $\begin{array}{l}\text { Described a "foraminoplasty" technique in which the working angle through the Kambin's } \\
\text { triangle is expanded by removing the ventral portion of the superior articular process } \\
\text { with reamers. }\end{array}$ \\
\hline 2005 & G.Choi ${ }^{26)}$ & $\begin{array}{l}\text { Percutaneous Interlaminar technique as alternative to transforaminal technique for } \\
\text { better access. }\end{array}$ \\
\hline 2007 & S. Ruetten ${ }^{27)}$ & Reported successful endoscopic decompression of foraminal pathology \\
\hline $\begin{array}{l}2001- \\
2021\end{array}$ & 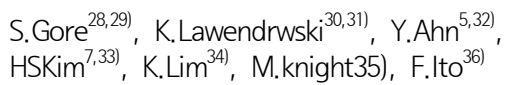 & $\begin{array}{l}\text { All of them are contributors to develop advance techniques and make Spine Endoscopy } \\
\text { popular in their respective region. }\end{array}$ \\
\hline
\end{tabular}


Though, further multicentric improvisation is needed for having a uniform nomenclature. The procedure is named in the following manner-approach corridor/visualization/segment of spine/procedure as per the consensus guidelines.

1. Full-endoscopic discectomy

a. Full-endoscopic cervical discectomy

I. Anterior endoscopic cervical discectomy (AECD)

i) Anterior endoscopic transdiscal cervical discectomy (AETdCD)

ii) Anterior endoscopic transcorporeal cervical discectomy (AETCCD)

II. Posterior endoscopic cervical discectomy (PECD)

b. Full-endoscopic thoracic discectomy

I. Transforaminal endoscopic thoracic discectomy (TETD)

II. Interlaminar endoscopic thoracic discectomy (IETD)

III. Retropleural Endoscopic transthoracic Discectomy (RETTD)

c. Full-endoscopic Lumbar discectomy

I. Transforaminal endoscopic lumbar discectomy (TELD)

i) Unilateral

ii) Bilateral

iii) Contralateral

iV) Bi-segmental

II. Interlaminar endoscopic lumbar discectomy (IELD)

III. Extraforaminal endoscopic lumbar discectomy (EELD)

2. Full-endoscopic foraminotomy

a. Posterior endoscopic cervical foraminotomy (PECF)

b. Transforaminal endoscopic lumbar foraminotomy (TELF)

c. Interlaminar contralateral endoscopic lumbar foraminotomy (ICELF)

3. Full-endoscopic lumbar lateral recess decompression

a. Transforaminal endoscopic lateral recess decompression (TE-LRD)

b. Interlaminar endoscopic lateral recess decompression (IE-LRD)

4. Full-endoscopic laminotomy for bilateral decompression

a. Cenvical endoscopic unilateral laminotomy for bilateral decompression (CE-ULBD)

b. Thoracic endoscopic unilateral laminotomy for bilateral decompression (TE-ULBD)

c. Lumbar endoscopic unilateral laminotomy for bilateral decompression (LE-ULBD)

5. Full-endoscopic Ventral Decompression

a. Transforaminal endoscopic Lumbar ventral decompression (TELVD)

b. Transforaminal endoscopic thoracic ventral decompression (TETVD)

6. Full-endoscopic assisted procedures

a. Transforaminal endoscopic lumbar annulopasty (TELA)

b. Trans-sacral Epiduroscopic Lumbar Discectomy (SELD)

c. Retropharyngeal endoscopic cranio-cervical decompression (RECD)

d. Transforaminal Endoscopic Lumbar Interbody Fusion (TELIF)

Other procedures which are still not categorised but described have been discussed individually as reported. Microscopic Or
Endoscope Assisted procedures are not incorporated except when FESS was used as the major component of the surgery (Type 6 of the above classification). Generation of endoscopes as evolved are used in all FESS (Rigid-Fibreoptic) and technological gadget enablers (Navigation, Laser, Burr etc) have not been individualised into category to avoid complexity.

In this review TELD is the representative index ESS which is discussed in detail. Other developments, innovations and extended applications of FESS are subsequently discussed separately and succinctly. Each procedure is discussed as a concept, its indication \& contraindications, technique, technical points with regard to advanced indications/innovations, advantages disadvantages with limitations, literature review, current standard of care and foreseeing future.

\section{Indications, Technique and Limitations}

\section{i) Lumbar FESS}

\section{(1) Transforaminal Endoscopic Lumbar Discectomy (TELD)}

The transforaminal approach refers to a posterolateral approach to the disc or epidural space through the foraminal window $^{45,46)}$. It preserves the essential posterior normal musculoskeletal structures. The most undisputed benefit of this approach is that it may provide direct access to certain stenotic points with or without negligible bone resection. More importantly, its possibility without general anaesthesia (GA) makes it unique. Technically precise insertion of needle to the disc through Kambin's triangle is the crux of the procedure. Its boundaries lies between the hypotenuse line made by the exiting nerve root; base made by the superior endplate of inferior vertebra; and altitude made by the medial border of thecal sac and traversing nerve root with an overhanging facet. The pedicle and respective disc space is chosen as radiographic landmark during any FESS procedure. More importantly it is to be imagined that the disc space is always ventral to the superior articular process (SAP). Based on cadaveric studies, the dimension of the safest and largest cannula in Kambin's triangle when placed at mid pedicular line is of $7.5 \mathrm{~mm}$ diameter in anteroposterior radiographic view, making it the most widely available cannula ${ }^{42,477}$.

Indications \& contraindications: The classical indication of this technique was soft lumbar disc herniation (LDH) of various types. With the advancement in technology and experience, its practical application has widened, to include migrated, recurrent, foraminal, extraforaminal, and even partially calcified LDH. This technique has been proven to be of significant benefit by many randomized trials, meta-analyses, and systematic reviews ${ }^{3,5,4855)}$. Contraindications are extensive migrated $L D H$, Central $L D H$, calcified discs, L5-S1 level (male patients, high iliac crests), multilevel pathology, spinal canal and foraminal stenosis, spondylolisthesis, recurrent LDH, nerve root anomalies such as conjoined root, profound motor deficit and cauda equine syndrome. These are relative contraindications and surgeons have used ESS in these as well ${ }^{3,8,31,32,34,40,56)}$.

The landing point of needle insertion in radiographic view is divided into vertical lines at medial, mid and lateral pedicular 
lines in antero-posterior view and posterior vertebral line in the lateral view. The medial pedicular line and posterior vertebral line are commonly used reference point for most of the TELD. Representative index TELD 'inside out' $(\mathrm{IO})$ technique will be elaborated here to discuss the classic original technique ${ }^{5,20,46,57-59)}$. Modifications and advances of approach will be discussed later.

Surgical technique: An independent anaesthesiologist should always be present during the whole surgical procedure even if it is done under local anaesthesia (LA) and conscious sedation. GA and regional anaesthesia (RA) are also employed by many institutes. The patient is put in protected prone position on a radiolucent table and supplemental oxygen is given. Prone position is preferred by most of the surgeons due to better anatomical orientation. Though lateral position is more comfortable for patient and is also practised by many surgeons. Pre-emptive, intramuscular midazolam $(0.05 \mathrm{mg} / \mathrm{kg})$ and diclofenac can be given. Titrated infusion of dexmedetomidine (0.5-1 mcg/ $\mathrm{kg}$ ) \&/or fentanyl (1 $\mathrm{mcg} / \mathrm{kg}$ ) of bolus followed by additional doses as needed are used.

A uniportal approach is used. A desired trajectory determination by extending a line from the target point bypassing the ventral facet to skin entry helps in planning of any transforaminal surgery on MRI axial section at upper endplate of lower vertebral level section ${ }^{60)}$. The angle between $20^{\circ}$ and $40^{\circ}$, and the puncture point of 9-14 cm from midline depending on the level of surgery and patient decubitus is usually done. The intended needle entry tract is infiltrated with 1\% lidocaine plus bupivacaine in 1:1 ratio. An 18-gauge needle is inserted fluoroscopically to the target point with continuous patient's feedback. The facet is usually touched first more towards the lower end plate and then a walking technique is followed for safeguarding susceptible neural boundaries. Trajectory can be changed by bevel of the needle, and cranio-caudal or dorso-ventral lift of the hub of needle before steering it further. $1.5-8 \mathrm{ml}$ further infiltration of the anaesthetic mixture on the annulus depending on patient feedback and difficulty of the pathology is needed. Constant communication with the patient eases out anxiety. Site of annular puncture is medial pedicular line in AP view and posterior vertebral line in lateral view in lower lumbar spine as inter pedicular distance (IPD) is wider. It is at mid pedicular line in upper lumbar levels as IPD is narrow. These understandings are to reduce the chances of dural puncture. Any undue pain radiating to the limb should warn surgeon of compression over exiting root and change the needle trajectory or the introduced working sheath. Traversing root is protected by the facet and it gets exposed only by "outside In (OI)" or "Flat endoscopic entry (FEE)" techniques. Now, the disc is entered. A discography can be done to differentiate the degenerated pathological tissue from normal tissue. A $7 \mathrm{~mm}$ incision is made and followed with tapered dilating trocar/obturator. The bevelled working cannula is railroaded, and then through that the endoscope is introduced. The removal of the offending compression is done at sub-annular location. Prolapsed disc excision is done from epidural space after releasing the firm annular anchorage with annular cutter. This is the 10 technique followed by most surgeons for LDH. Precise differentiation of anatomical layers, the herniated disc, annular fissure, posterior longitudinal ligament (PLL), neural tissues, facet, ligamentum flavum (LF), fat and pedicular notches are the key to safe execution under vision. Straight and articulated instruments are used to tease, grab, deliver the culprit fragment. It should be removed completely without any loose pieces in the epidural and intradiscal space. The decompression endpoints are inferred with complete visualisation of the roots, dural sac, free mobilization of the neural tissue, probing, strong dural pulsations, irrigation flutter, fresh epidural bleed, subsidence of pain, MRI matched retrieved fragment and cough impulse ${ }^{3,7,59)}$. Skin incision is closed and all patients are mobilised as per their tolerance and limb power. Patients are then advised to undertake passive/ active physiotherapy. All patients should be sent for MRI to confirm decompression and rectify any residue if needed.

Advances in TELD: There are numerous techniques with subtle modifications employed depending upon the training, type of $\mathrm{LDH}$, level and location. Standard basic techniques of Ol or FEE are used.

In case of settled disc space, sequential dilator is more easily positioned to avoid pain ${ }^{29,61)}$. Blind (only fluoroscopy guided) non-visualised reamed foraminoplasty using trephines or spiral bone reamers can be done to reach epidural space directly ${ }^{25,61-64)}$. This is called Ol approach. Epidural bleeding, and early confusion of anatomical/pathological discrimination of the visualised structures is the inhibitory factor for beginners in this technique. Safe engagement is key to success. Therefore, "Ol" or foraminoplasty technique is regarded as more challenging than 10 endoscopic discectomy $y^{5)}$.

A FEE approach can be taken nearly at an angle of $0^{\circ}$ landing in the epidural space avoiding the piercing of the disc and facet reaming. This is a far lateral approach. This is done for direct removal of the dislocated nucleus piece (extruded or sequestrated low migrated) in central, paracentral or low migrated or foraminal and extraforaminal location ${ }^{6)}$.

An endoscopic visualised burred foraminoplasty (BF) or Ol approach is taken when there is a technical requirement to reach more dorsal in epidural space ${ }^{59,61,65,66)}$. A recent mobile Ol technique described does not focus on any enlargement of foramen but on the precise placement of the cannula within the foramen ${ }^{67,68)}$. The advanced indications of the TELD/TELF/ICELF need foraminoplasty (Figure 1).

Special modification of the standard technique are needed to tackle other special situations, extra foraminal LDH and high grade up/down migrated LDH and high iliac crest for L5-S1 level ${ }^{3,5,69,70)}$. Foraminal and extraforaminal LDH: the needle trajectory is to be kept steeper, entry point should be a 5 to $8 \mathrm{~cm}$ from midline and lateral or mid-pedicular line on AP fluoroscopy directing towards superior end plate of caudal vertebra or the centre of disc ${ }^{3,71,72)}$. Furthermore, the less perpendicular variations of the trajectory can increase the distance of the skin entry point from the midline compared with traditional approach and even keep a coronal-caudal angle of 15 to 20 degree. Using an exiting nerve root retraction technique by rotation of the bevelled cannula this manoeuvre additionally protects the innocent nerve. But this technique will encounter difficulties 
for L5-S1 location. Ruetten et al., though have rou- tinely used an extreme lateral entry successfully for foraminal and extraforaminal $\mathrm{LDH}^{51}$. A reported success rate of $85 \%$ using the shallow approach for a mixed group of foraminal and extraforaminal DH is available in literature ${ }^{73)}$. Satisfactory result rate over $90 \%$ is reported in few series ${ }^{72,74)}$.

In migrated DH the needle entry point and target point should be caudo-cranial for up migrated disc herniation and cranio-caudal for down migrated $\mathrm{DH}$. This is done after the primary "IO" technique. After completion of the sub-annular decompression the endoscope is angulated towards the migrating fragment. The half-and-half transforaminal technique for near migrated $\mathrm{DHs}$, is based on annular release and leveraging of the working sheath ${ }^{68,75}$. For very high grade down migrated $\mathrm{DH}$, foraminoplasty or oblique pediculotomy (suprapedicular removal of superior and medial wall of the lower pedicle) may be needed (Figure $2,3)^{3}$. Success rate of the surgery in the high grade inferiorly migrated $L D H$ is low due to remnants of the disc fragment ${ }^{25,26,33,75-79)}$. If needed ventral vertebral body spurs of bone are removed to reach to the fragment directly ${ }^{33,75,78,79)}$. Transpedicular discectomy (direct pedicular approach without going at discal level) for down migrating LDH is reported as well ${ }^{68,80,81)}$.
In L5-S1 LDH, TELD is a demanding procedure due to iliac crest, $L 5$ transverse process, hypertrophic facet joint, smaller foramen and sacral ala. The major landmark in preoperative planning should be the height of the iliac crest with reference to the $L 5$ pedicle ${ }^{822}$. Precise preoperative trajectory evaluation method using magnetic resonance imaging (MRI) or computed tomography (CT) examinations can be of help ${ }^{83}$. A surgical approach classification based on radiographs can guide for the allocation of patients to either supra-iliac or trans-iliac approach ${ }^{84)}$. In spite of the preoperative planning if a per-operative difficulty is noted then conversion to a trans-iliac or inter-laminar approach should be considered immediately. It is performed in the prone position under LA and sedation. A transverse line is drawn at the upper end plate of S1 body under antero-posterior view fluoroscopic guidance. Another oblique line can be drawn along the disc space in the lateral view. The point of intersection of these two lines is the starting point which is $12-15 \mathrm{~cm}$ from the midline. Alternatively, if Ferguson view (oblique view with overlapping anterior and posterior endplates of S1) is used then the lateral point and obliquity will get accommodated and directly the entry can be decided as per the MRI section at the L5 upper end plate level and pathology location giving an idea about the landing
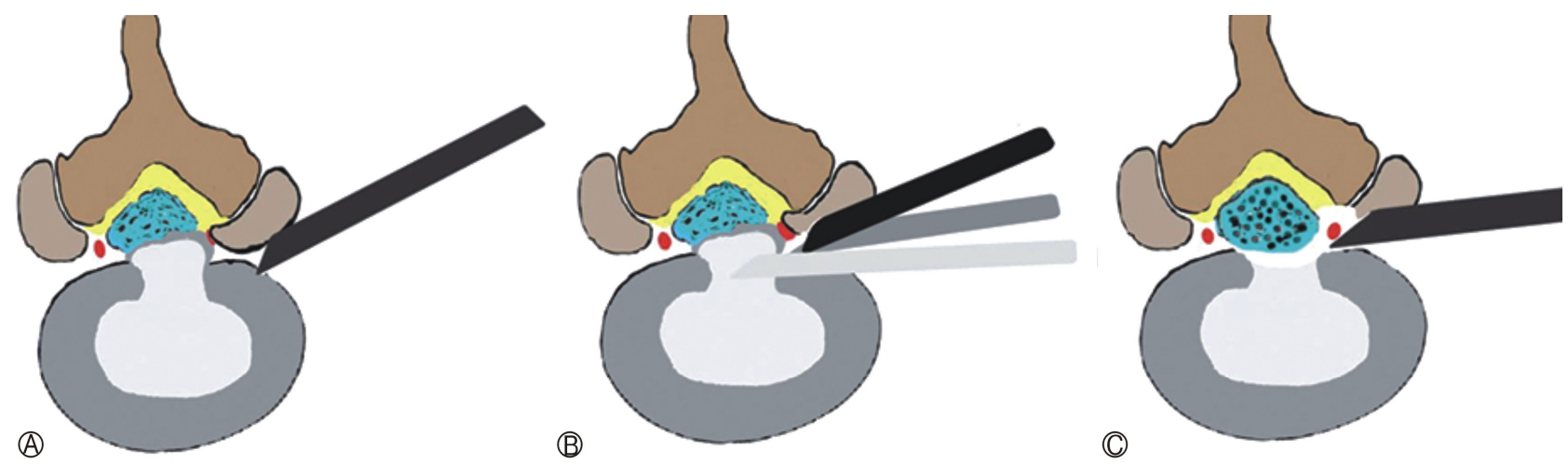

Figure 1. The typical transforaminal 'inside out' approach leads the endoscope to posterior one third of the disc. (A): Central disc or osteophytes from ventral aspect, SAP and ligamentum flavum hypertrophy contributing to lateral and central stenosis. A transforaminal endoscope lands lateral to the pathology and going inside addresses only ventral pathology partially. (B): Foraminoplasty and joy-sticking of the endoscope allows medialization, dorsalization and horizontalization. Three necessary steps for dealing with epidural compression (soft or hard) ventrally and lateral recess decompression.

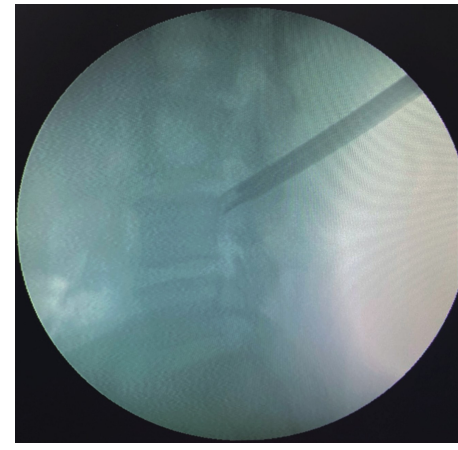

Figure 2. Oblique pediculectomy position of endoscope for high migrated $\mathrm{LDH}$.
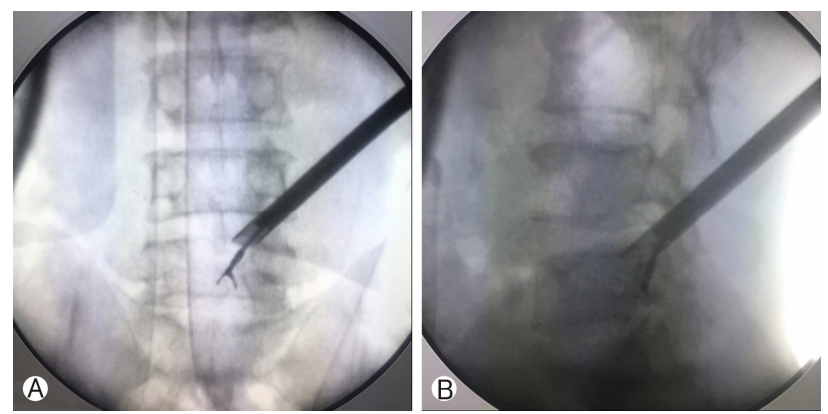

Figure 3. C arm images showing a foraminoplasty approach for Very high migrated Disc L45. Steerable grasper position in epidural space in antero-posterior (A): \& lateral (B): view. 
point distance. Tip of spinous process can also be taken as arbitrary point. The further process of aiming is, as if we are doing any other level of lumbar surgery to reach the medial pedicular line. LA is injected into the skin, subcutaneous tissue, muscle and to the periosteum of the posterior ileum with a long spinal needle. Then a Jamshidi needle is used to reach to the iliac crest in the planned trajectory under fluoroscopic guidance. An 8 $\mathrm{mm}$ stab incision is used. This Jamshidi needle is hammered into ilium and the inner cortex is then injected with local anaesthetic. The trocar of Jamshidi is withdrawn and the TF needle is introduced to reach the facet or the disc and LA is again instilled. The long guide pin is inserted further through the TF needle to the achieved location. Sequential reaming is done with reamers till $8 \mathrm{~mm}$. After reaming obturator is inserted and final repositioning can be done according to the need. Then further an "IO" or "Ol" is done as per the need. Trans-iliac approach is safe and effective in lumbosacral LDH and removes the limitations of supra-iliac TF approach for L5-S1 disc space in the reported case series by Mahesha et $\mathrm{al}^{70)}$. In a cadaveric study followed by clinical series of 15 patients feasibility was proven by Osman et al. Post-operative dysesthesia (POD) occurred in 2 cases which resolved after 3 weeks. L5-S1 DH can be approached by supra-iliac window in patients when there is a feasible low iliac crest ${ }^{26,84}$. Still, foraminoplasty may be needed for central massive disc in these cases. This is due to the fact that the inter pedicular distance is higher at $L 5 / S 1$ and facet may be bulbous. This can in fact lateralise the oblique working sheath and difficulty to medialise the tip of endoscope leading to more $\operatorname{POD}^{70,84,85)}$. Hyperkyphotic placement in prone position helps as well ${ }^{61)}$.In patients with high iliac crests, foraminoplasty to enlarge the foramen using endoscopic bone cutters with the intent of reducing the occurrence of exiting nerve injuries is suggested ${ }^{82,86)}$. The chances of iatrogenic endplate injury increase when the cannula is not in line with the disc inclination. Most of the contraindications are now getting challenged by pioneers and getting reported sporadically ${ }^{56,66,87-89)}$. In bilaterally symptomatic cases, there may be inadequate decompression from index approach due to limited reach to opposite ventral side in some cases like calcified disc or cauda equina syndrome. Then in the same stage or second stage, opposite side TELD can be un- dertaken ${ }^{59,90)}$. Increasing the water pressure by sealing the endos- cope to raise up the

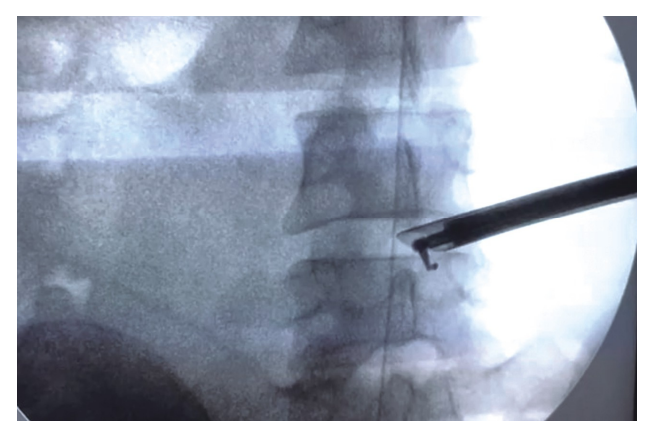

Figure 4. Hook can be used to swipe the floor. This helps to check the smooth floor of the endoscopic approach after decompression. dural sac and revealing the contralateral nerve root in bilateral symptomatic patients is a crucial step ${ }^{87)}$. A hook is a good tool to swipe the floor (Figure 4).

Calcified disc stenosis is also amenable by TELD ${ }^{91)}$. It needs use of burr and endoscopic osteotomes and can be removed by piecemeal approach (Figure 5$)^{59)}$. Calcified tissue of the disc can be reamed away during foraminoplasty approach itself ${ }^{61)}$. In extraforaminal/ stenosis the optimal bony decompression work in extra-canalicular area using burr, trephines and cutters removes the bony spurs, collagenised disc while protecting the exiting nerve root ${ }^{92)}$. In presence of $\mathrm{LDH}$ with scoliosis, the Carm should be rotated relative to the patient to obtain good antero-posterior and lateral images, and the entrance point should be medialised or lateralised according the rotation of vertebra $^{61)}$. Obese patients need lateral entry, longer endoscope and better C-Arm imaging. Incidental durotomy has been reported as a frequent complication in obese patients ${ }^{93,94)}$. It may additionally be due to more fat in epidural space leading to an impairment of vision during the procedure.

TELD has been used in spondylodiscitis and postoperative spondylodiscitis effectively the last two decades ${ }^{95-97)}$. Even for anterior epidural abscess of thoracolumbar spine TELD, its safe outcome is reported $^{98)}$. In literature of chronic low back pain (LBP), controversially the significance of high intensity zone (HIZ) in posterior annulus visualized in T2 weighted is being reported and evolving ${ }^{99-107)}$. Inflammatory granulation tissue has been noted in the histology. Active inflammation mediating pain through free nerve endings has been confirmed during recent studies $^{103,104)}$. TELD has been used in treatment of discogenic LBP ${ }^{106)}$. FESS Annuloplasty of HIZ as a treatment for LBP is reported ${ }^{107)^{\circ}}$.

Bipolar cold coagulation/radiofrequency helps in evaporating soft culprits and Ho-YAG laser can ablate hard tissue also and expedite surgery, Endoscopic epidural visualization and using lasers to vaporize the disc fragments was popularised in $1990^{\prime} \mathrm{s}^{3,46)}$. However, after the initial enthusiasm lasers fell out of favour due to wide arc of deflection and neural injury ${ }^{68)}$.

\section{2) Transforaminal Endoscopic Lumbar Foraminotomy (TELF) Transforaminal Endoscopic Lateral Recess Decompre- ssion (TE-LRD)/Transforaminal Endoscopic Lumbar Vent- ral Decompression (TELVD)}

The most common pathology of the degenerative stenosis is hypertrophy of the SAP, LF hypertrophy, disc space settling (annulus buckling) with or without LDH, osteophyte formation and associated dynamic or static instability, 56, 108, 109). As a result, the traversing nerve root is compressed in the lateral recess stenosis and the exiting nerve root is compressed in the foraminal stenosis. Lumbar spinal stenosis (LSS) according to pathological zones is classified into three categories: central stenosis, lateral recess stenosis, and foraminal stenosis. Until now Microscopic lumbar discectomy (MLD)/Open discectomy (OD) decompression have been considered the gold standard surgical options for treating these types of problems ${ }^{109)}$.

The TELD approach seems to give good results for the treatment of LSS also. But, this approach may be less effective for 
LSS patients who have lumbar instability or require revision surgery in the same segment. The time tested lumbar fusion surgery with decompression has a high fusion rate, but with obvious great damage to the muscles and facet joints in open surgery. Although this collateral damage is less in MIS fusion, but it still exists. With mechanical stress on above or below disc, adjacent segment degeneration may occur ${ }^{911}$. Elderly patients are prone to internal fixation failure with severe osteoporosis and sarcopenia marring the final outcome is also not uncommon ${ }^{66,91,110)}$.

The transforaminal endoscopic approach can be suitable for the treatment of the lateral recess/foraminal stenosis by resection of the hypertrophied $S A P^{5,66,91,111)}$. Reaching to the central dorsal aspect is difficult by transforaminal approach. Though indirect decompression by removing the ventral upper endplate spur of lower vertebra can enlarge the central canal also ${ }^{65,111)}$ (Figure 6).

Technique: Like for LDH, in the same way needle positioning followed by docking the working cannula is done but usually within the foramen on the facet and not in the intradiscal space. Typically, a foraminoplasty approach is undertaken. This is done under $15-20 \mathrm{ml}$ of more LA agent. The docking is done in the lower foramen at the caudal surface of the SAP and supra-pedicular notch. The tip of the SAP is removed by bone trephines or reamers. It is done blindly under fluoroscopic control with medial pedicle line as the limit and the give away feeling suggests the completeness of bony resection. It though appears risky and doubtful for non-believers and early novice endoscopy surgeons, but there is a soft curtain of capsule and LF still intervening between the advancing sharp reamer and the traversing root. Visualised endoscopic burred foraminoplasty can also be done, which is apparently safe. But with burred foraminoplasty alone, it takes more time and traversing root neuropraxia can occur. Best use is using trephine followed by fine burr usage. After sufficient removal of the bone, the exposed LF and capsule are removed by dissectors, cutters, micro-punches and forceps. For foraminal stenosis the focus is in the cranial foramen and removal of the tip of SAP, capsule and LF. Visualisation of the pulsatile exiting nerve root is the end point of decompression. For the lateral recess stenosis, the caudal foramen is focussed, and additional adjoining pedicle removal is needed many times in
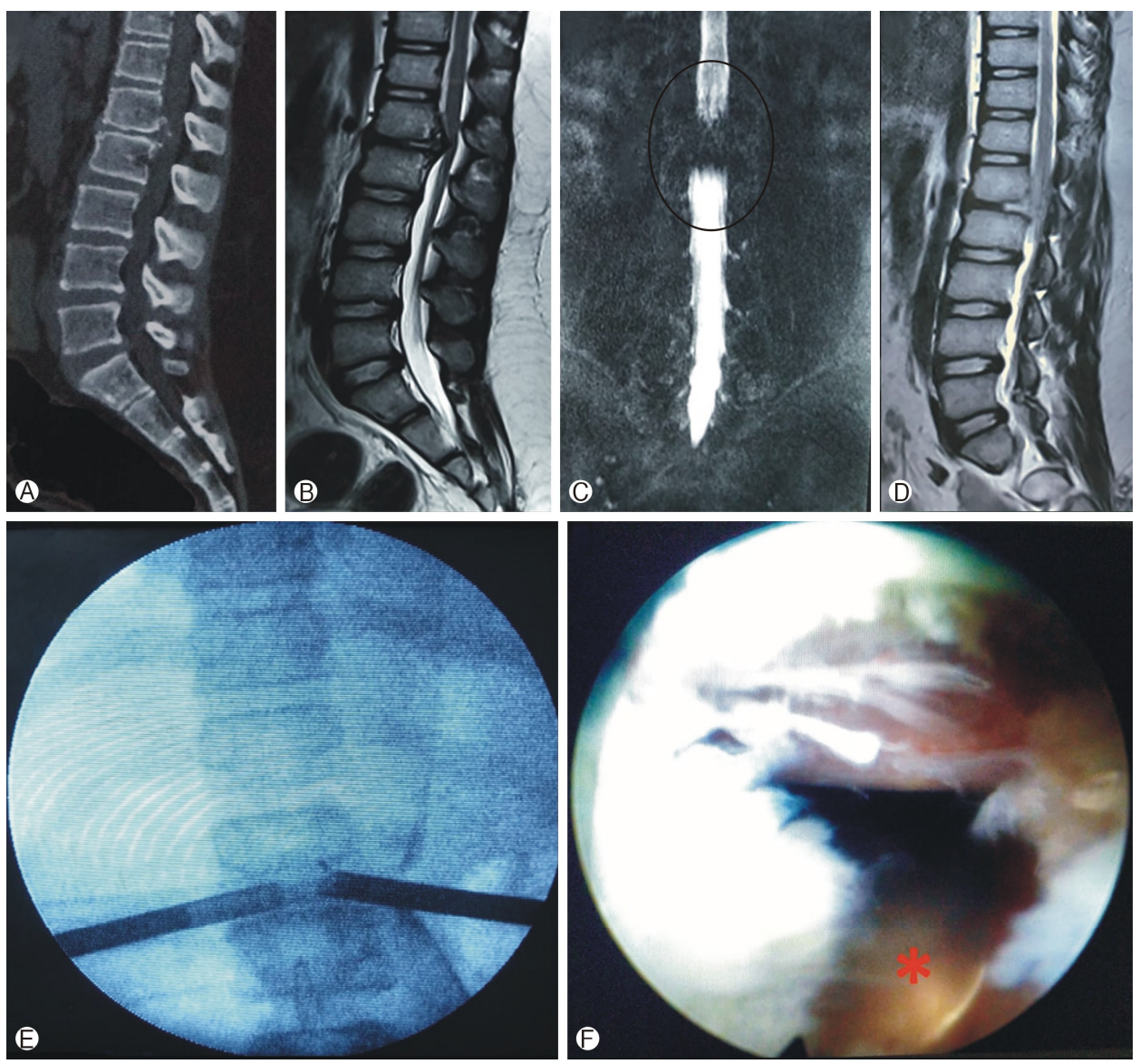

Figure 5. (A), B, (C): Conus syndrome in a 19 year boy, non-walker paraparetic with bladder affection. CT Scan axial section, MRI T2 Sagittal and MR meyelogram showing calcified disc complex with severe compression. (D): Post-operative MRI showing complete decompression. (E): Bilateral biportal transforaminal approach taken under Local anaesthesia. $\circledast$ : Intra-operative endoscopic view with decompressed cord and opposite working cannula $\left({ }^{*}\right)$ 
addition to SAP, IAP, LF and capsule. Visualisation of the entire pulsatile traversing root on ventral, lateral and dorsal aspect confirms adequacy of decompression. This is lateral and dorsal decompression. For central stenosis ventral decompression by removal of the LDH, buckling annulus (which is usually hardened or calcified) and removal of the superior vertebral end plate spur of the inferior vertebra is done with use of burr, endoscopic osteotomes and curettes. Visualisation of the entire pulsatile traversing root and central dura affirms the adequacy of decompression. For bilateral symptomatic cases further flattening of the endoscope trajectory and ventral decompression of contralateral traversing root and visualisation is to be done.

Successful clinical outcomes with full-endoscopic surgery for the specified indications have been reported for LSS ${ }^{1133}$. In a case series of 85 patients having lumbar lateral recess stenosis with or without combined LDH foraminoplasty and TELD yielded $90.6 \%$ satisfactory outcome ${ }^{1111}$. However, some unfavourable outcomes like, incomplete removal of LDH (up to $2.8 \%$ ), a steep learning curve, and recurrence (5 to $6.2 \%$ ) have been reported $d^{51,114-117)}$. Elderly patients (age $\geq 60$ years) and patients with diabetes had a higher risk of surgical failure during a FESS ${ }^{118)}$. In one of the series of 45 patients with lateral recess stenosis $(n=22)$, central stenosis $(n=13)$ and foraminal stenosis $(n=10)$, good overall outcome was achieved. However, they have reported poor outcome in patients with severe stenosis ${ }^{911}$. TF approach or zygapophyseal joint cysts located at extraforaminal and intraforaminal location affecting the exiting nerve root at this level can also be dealt with a far lateral entry ${ }^{119)}$.

The axilla between the traversing and exiting nerve is the location of the missed patho-anatomy in patients with lateral recess stenosis and hides the pain generators. The complete decompression of this "hidden zone" of pathology obviates the symptoms and is another recommendation ${ }^{120)}$. TELD in degenerative spondylolisthesis is less reported. It is not extensively possible to remove complete posterior LF and subarticular stenosis but it can be addressed optimally (Figure 7) ${ }^{66}$. Patients with little or no back ache, with re-stabilization signs (osteophytic fusion, dry facetal arthrosis, gross disc space narrowing, non-major facet
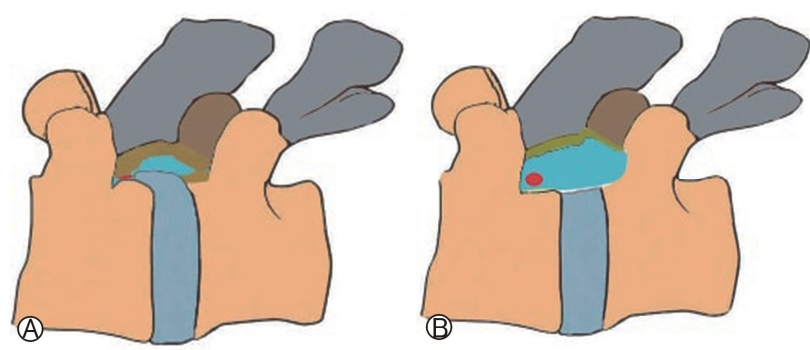

Figure 6. The various components of stenosis (A) can be addressed here by transforaminal approach (B). Ventral Caudal(end plate spur), Ventral Disc and annulus and postero-superior corner and end plate of caudal vertebra contributing to central stenosis. Dorsal superior pediculo-facet junction, facet overhang and ligamentum flavum contributing to the lateral recess stenosis. Ligamentum flavum, tip of superior articular processes and Ventral cranial (end plate spur) contributing to foramina stenosis. effusion, lordotic disc angle on dynamic radiographs, and less than $3 \mathrm{~mm}$ translation are all signs of a stable spondylolisthesis) can be saved from a fusion surgery. Though, progression of stenosis can occur further in these cases in later life. But, the patients needing fusion are those with potential instability or unstable spondylolisthesis ${ }^{1211}$. This is logical and well understood but less followed. The patients of spondylolisthesis who wants moderate improvement without going through major intervention, may be offered TELD as an intermediate procedure ${ }^{88)}$. The surgery by TELD can decompress the ventral stenosis unilaterally or bilaterally and the ipsilateral lateral recess dorsal stenosis as wel| $16,88,8,112,122)$. But, it cannot address the opposite side lateral recess stenosis. A bilateral approach has also been mentioned for endoscopic decompression addressing bilaterally symptomatic spondylolisthesis with addition of percutaneous fusion ${ }^{123)}$.

TELIF surgeries when indicated for instability and backache can be executed under local or regional or general anaesthesia. This is done after adequate decompression surgery or solely relies on indirect decompression with restoration of disc height without decompression. Long-term results with fusion surgery are awaited though it looks highly promising in the initial reports ${ }^{66,123-129)}$. When done under general anaesthesia intraoperative neuromonitoring is mandatory ${ }^{123,126,128)}$. In spite of having followed neuromonitoring protocols, the incidence of dysesthesia and neurological worsening are discouraging and may be due to non-visualized expansion of the Kambin's triangle in addition to the larger size port used (though this expedites the interbody bed preparation and assists the indirect decompression with expandable cage insertion) ${ }^{126-128)}$.

Complications \& limitations: The cost of the instruments and procedure are significant. The radiation exposure associated with TELD is more than other minimally invasive techniques. Although the procedure has good efficacy, complications may occur which are infrequent as well as unique at times. The complications can be classified as per-operative (local and systemic) and delayed (early and late). Injury to exiting nerve root, traversing root
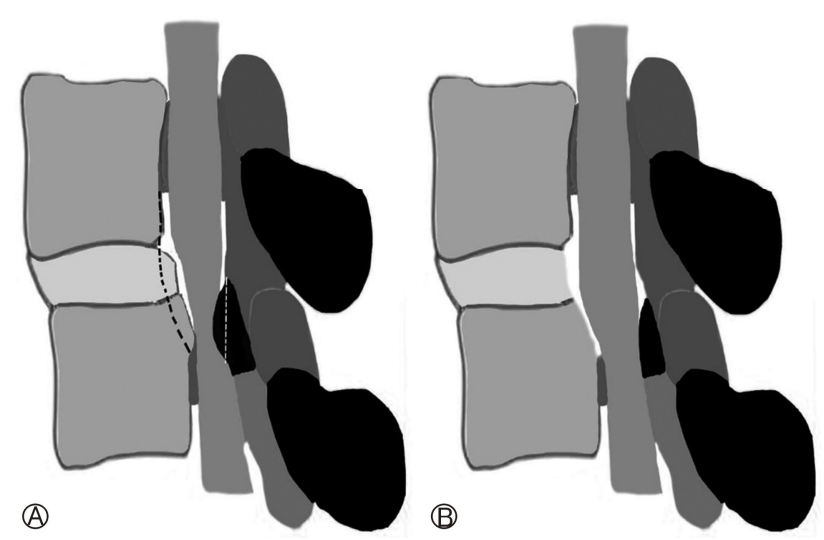

Figure 7. In stable listhesis showing components of stenosis (A). Removal of the supero-posterior corner of inferior vertebra with annulus when combined by FESS foraminoplasty with removal of ligamentum flavum and facet overhang adequately does the decompression work, especially in elderly (B). 
or central rootlets, dural tears, vascular injury (major vessels or segmental twig in the foramen), peritoneal content injuries, missed/residual fragments, pedicle/facet injury, instrument related complications, wrong level surgery, seizures, posterior neck pain are per-operative complications that are reported ${ }^{7,130-132)}$. $P O D$, residual pain, other level or opposite side new disc prolapse, epidural hematoma, retroperitoneal hematoma, dyspnoea, spondylodiscitis, psoas abscess, pseudocyst, recurrent LDH, low back pain and instability are although infrequent but reported ${ }^{7,131)}$. There are several suggested technical guidelines to increase the effectiveness of TELD and to prevent its complications ${ }^{7,133,134)}$. The risk of unexpected adverse events may increase as surgeons starts performing TELD and broadening its indications to greater complexity. Hence, resultant early failures would be high ${ }^{4,131)}$. The suggested tips are many and not only limited to choosing the correct case and improved MRI reading, avoiding retroperitoneal trajectory and following "walking technique" after touching the facet, working in the lower foramen, change needle if accidental peritoneal puncture has happened to prevent spondylodiscitis, landing as close to the LDH as possible according to the type of $\mathrm{LDH}$, releasing tight annular anchorage around the hernia before pulling it out, following all steps meticulously, using foraminoplasty judiciously to change the trajectory (or to improve the endoscope reach or for attaining stenosis decompression) and confirming adequacy of decompression by following the endpoints of decompression.

\section{3) Inter Laminar Fess: Interlaminar Endoscopic Lumbar Dis- cectomy (IELD)/Interlaminar Endoscopic Lateral Recess Decompression (IE-LRD)/Interlaminar Contralateral Endos- copic Lumbar Foraminotomy (ICELF)}

The interlaminar (IL) approach or IELD was proposed after TF technique to overcome its apparent limitations and early contraindications. Initially, for the treatment of LDH at the L5-S1 level. This further contributed to expand the indications of ESS, especially in treating spinal stenosis of all regions. The IL approach for lumbar discectomy was being done with the aid of microscope $^{18,135,136)}$. Therefore, IELD was initially considered to be an evolved form of MLD ${ }^{137)}$. Choi's technique was a blind technique on targeted needle in epidural space and could not be performed under direct visualization ${ }^{26)}$. There were problems with the small working channel in the endoscope and lack of durable instruments for bone resection. When combined with a narrow interlaminar window this resulted in limited indications for the first generation endoscope system. However, with second generation wider endoscopic system and the "stenoscope" with a $5.7 \mathrm{~mm}$ working channel, the manuverability and possibilities have evolved the technique of IELD. But, it is to be remembered that on the contrary to TF approach where the neural tissue appears in vision after decompression, in the IL approach neural tissue needs manipulation to reach to the herniation. Thus, IELD demands more meticulous technique to avoid neural complications. The IL window width exceeding $20 \mathrm{~mm}$ is usually good for IELD ${ }^{138)}$. The stenoscopic system (Percutaneous stenoscopic lumbar decompression-PSLD) provides efficiency in bony rese- ction even when the IL window is small $(<8 \mathrm{~mm})^{34)}$.

Indications \& Contraindication: LDH (paracentral or foraminal) from L2-S1 level, calcified LDH, upward or downward migrated LDH, LSS without significant instability, central canal stenosis, LF hypertrophy, lateral recess stenosis, foraminal stenosis, synovial cysts and hypertrophic facet. Except general surgical contraindications, there are none specific to the procedure.

Technique: Local anaesthesia can be used but regional or GA is preferred. It is done with the patient in prone position under radiological control. The image intensifier is set into Fergusson's view. The interlaminar window is marked in AP view and a skin incision of $5 \mathrm{~mm}$ is made in the cranio-caudal middle of the IL window as much medial as possible. A dilator of $6 \mathrm{~mm}$ outer diameter (without any needle, as against the initial pioneering technique), is inserted bluntly to the lateral edge of the IL window. Over this, a beveled working sheath of $7 \mathrm{~mm}$ outer diameter is inserted by railroading. The bevel opening is directed medially toward the LF. Endoscope assembly is inserted, and the further procedure is performed under vision with constant irrigation. A cutter is used to make lateral incision in the LF, which is enlarged usually around to $5 \mathrm{~mm}$. Epidural space with the neural structures and the epidural fat tissue is exposed. The LF splitting technique may cause transient weakness. Moreover, the blind spot may limit visualization resulting in residual fragments. The beveled working sheath is used as a second instrument and rotated to work like a nerve hook ${ }^{139)}$. The axilla approach can relieve the compressing pressure partially before the nerve root retraction. This "Rotate and Retract" technique gives visual control and is a standard procedure to protect nerve root and dural sac during discectomy ${ }^{140)}$. Visualized splitting of LF is a proposed method ${ }^{141)}$. Another modification with blunt dissector is also suggested ${ }^{142)}$. Medio-lateral and cranial-caudal mobility is controlled on vision applying the joystick principle. The medial edge of the descending facet/ascending facet is prepared with burr and punches. The LF is removed with punches depending on the patho anatomical features if needed for discectomy. Radiofrequency electro-coagulator for haemostasis, clearance of soft tissue, annulotomy, and annuloplasty is used. Typically, the area between pedicle to pedicle of one segment can be decompressed (Figure 8) ${ }^{143)}$. For stenoscopic decompression, through a $7 \mathrm{~mm}$ vertical skin incision, and a blunt dilator that serves as a guide for the $9.5 \mathrm{~mm}$ outer diameter working sleeve is advanced just beside the spinous process at right angle. Subsequently, a working sheath follows on a dilator and a stenoscope ( $8.4 \mathrm{~mm}$ outer diameter, $12^{\circ}$ view) is introduced. The epidural space is opened directly via a laminotomy, and the LF and medial part of SAP is removed to expose the traversing root. A $4 \mathrm{~mm}$ drill, dissector and $5 \mathrm{~mm}$ Kerrison punch through the $5.7 \mathrm{~mm}$ working channel of the stenoscope is used. Laminotomy is performed to expose the uppermost portion of the LF, and a dissector is used to release it. As much of the LF as possible is removed. After the ipsilateral decompression, the contralateral LF and superior articular process are removed to decompress the contralateral traversing nerve root $^{34)}$.

Complications and limitations: Surgeons usually attempt more 
aggressive discectomies to try to reduce the incidence of recurrences. This approach might cause more post-operative accelerated severe degeneration and back pain ${ }^{144)}$. The curettage of disc space leads to end-plate injury and collapse of disc, furthering intervertebral instability, thus contributing to the post-operative back pain. Secondly, the unavoidable neural manipulation, which accompanies this manoeuvring has to be safely titrated. Retraction of neural structures is unavoidable and may lead to deficits or POD. Careful study of the MRI and avoiding retraction of the root towards any compression are important in this regard. This can be done by choosing on the type of LDH i.e. axillary, shoulder or ventral LDH ${ }^{145)}$. Complications such as POD, transient weakness, and bladder-bowel disturbance are reported in IELD. More ventral-type technique with lesser manipulation via the shoulder or surrounding nerve root discectomy are suggested technical modifications for best outcome ${ }^{146)}$.

Advances: The mobility of IELD provides broad indications in dealing with all kinds of patho-anatomies and various kinds of stenoses equivalent to or more than MLD. With overhanging lamina, laminotomy to widen the interlaminar window can be done. Different sizes of endoscope to reach far-migrated disc fragments is possible. IELD/IE-LRD/ICELF has focused on degenerative lumbar pathologies. It is continuously evolving and getting standardized. If exiting root is to be decompressed, the ICELF is feasible to perform SAP tip removal and the lateral half of the foraminal LDH or far-lateral LDH removal can be accomplished. Stenoscopic decompression of the central and lateral recess spinal stenosis over the top (over the top decompression) and removal of any type of LDH simultaneously is possible (Figure 9). Furthermore, jumping technique via uniportal access through one skin incision which decompresses 2-3 levels of the stenosis concomitantly is also possible ${ }^{34)}$. To treat foraminal and extraforaminal stenoses with or without DH, a Para PSLD (paramedian) approach is used. Under fluoroscopic guidance, with a 7-mm incision 4-5 cm lateral to the spinous processes (the incision point may vary depending on the lesion location), exposing the lumbar

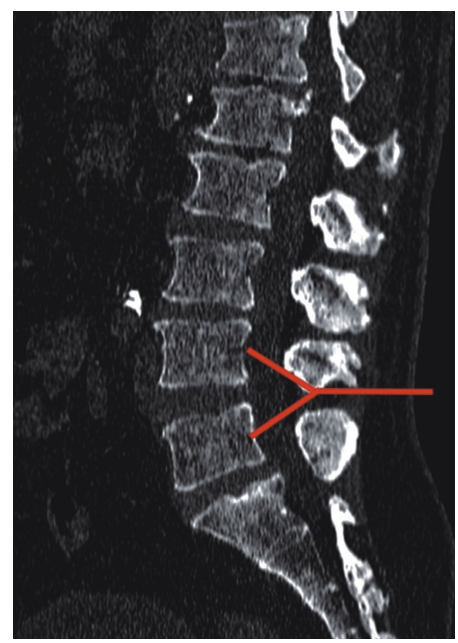

Figure 8. In interlaminar decompression, pedicle to pedicle decompression possible on the ipsilateral and contralateral side. foraminal or extraforaminal zone via a para PSLD approach. Indication of this procedure is not the LDH but the bony stenoses and thickened foraminal ligaments trapping the exiting nerve root. Thus, the target point of the dilator, working sleeve and endoscope is docking at the lateral margin of the ipsilateral side isthmus. The superolateral part of the superior articular process (SAP) is resected using Kerrison punches and a burr. The endoscope is tilted toward the medial side and the lateral isthmus portion and superomedial SAP are resected. This creates space for the stenoscope to work. The dissection up to the upper pedicle is done and intertransverse and foraminal ligaments to expose the affected exiting nerve root. This is usually done for the L5 nerve root. The decompression is from the medial part of the SAP to the sacral ala. Vertebral body osteophytes are removed using burr, and partial L5 or S1 pedicles are also removed if needed. The radicular artery may be coagulated for haemostasis. The lateral edge of the LF is also removed. The dissectors and freers are used. For extraforaminal stenoses, by tilting the stenoscope laterally, additional extraforaminal decompressions is completed $^{147)}$.

\section{ii) Thoracic FESS}

Thoracic disc herniation (TDH) is an uncommon entity although frequently disabling when symptomatic. Its treatment has been approached classically by open circumferential approaches ${ }^{148-152)}$. But, the thoracic cord doesn't tolerate manipulation unlike lumbar. Moreover kyphosis and precarious blood supply adds to valid woes of the surgery which if not taken care may raise the devastating complications as high as $25 \%{ }^{152-154)}$. The use of minimally invasive techniques in treatment of spinal stenosis secon-
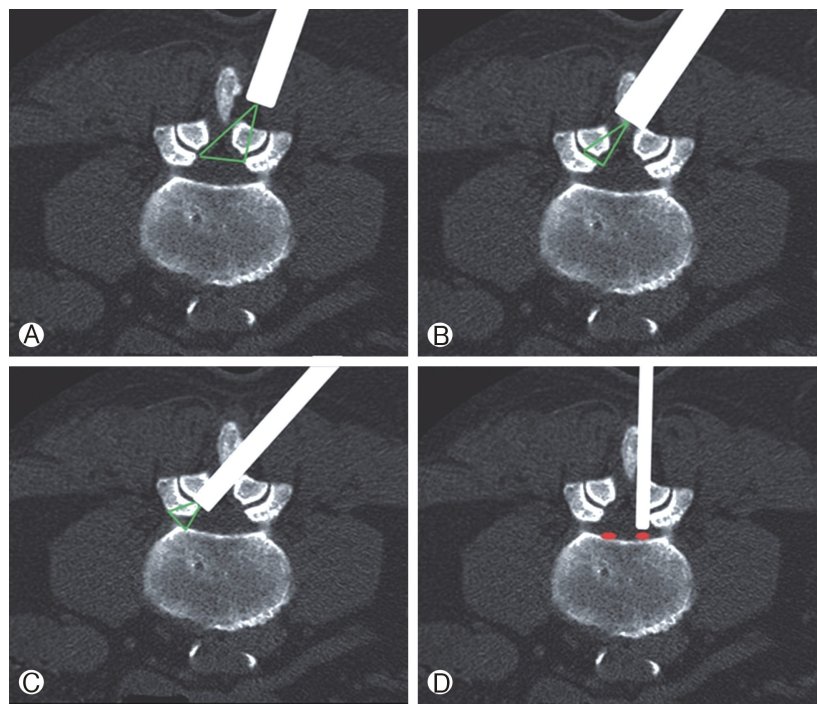

Figure 9. Interlaminar Decompression: (A): Central/ or unilateral Laminotomy, (B): Contralateral decompression, (C): Contralateral Foraminotomy. Smaller endoscope preferred (D): Ipsilateral ventral decompression. It is to be noted that the ventral decompression is done with retraction of the root from shoulder or axilla. Smaller endoscope preferred. 
dary to ossified LF has been well described but infrequently used due to the technical challenges ${ }^{155)}$. The thoracoscopic approaches (Video assisted thoracoscopic techniques-VATS) provide the best visualization and adequate access to the pathologies but requires the use of multiple ports for visualisation, may need instrumentation and always needs a post-operative chest drain. There are chances of pneumothorax, persistence of dural leak and single lung ventilated general anaesthesia is required ${ }^{156,157)}$.

Trans-facetal pedicle sparing approach \& transpedicular approach although sparingly are reported ${ }^{158)}$. These descriptions are not of full endoscopic procedures and are more of microscopic or endoscopy assisted procedures and have variable facet or pedicle removal. In future it may assume the complete FESS role.

Indications and contraindications: The major reported use of FESS in thoracic spine is limited to indications pertaining to soft TDH in paracentral and lateral locations. The sporadic indications have now started to include thoracic spinal stenosis (TSS) due to central LDH, calcified LDH, OLF and ossified posterior longitudinal ligaments (OPLL). It is worthwhile to note that these extended indications once formed contraindications to endoscopy. Generally, patients with profound neurological deficits due to significant myelopathy, history of previous spine surgery and multi-level involvement are few contraindications for this type of surgery ${ }^{159)}$. TETD though has been recently contraindicated in patients with severe acute or progressive myelopathy due to hard or calcified disc herniation, OPLL and severe disk narrowing, Costotransverse joint needs to be drilled to widen the access in most of the cases ${ }^{160)}$. Absence of CSF buffer and more susceptible cord tissue to heat injury and laser is to be considered $^{3,60,160)}$.

Techniques with Advantages and Limitations: The techniques of FESS in thoracic spine depends on the pathology type and location. Thus, it depends directly on the type of approach used for accessing the pathology (Figure 10). The commonly used types are: Transforaminal endoscopic thoracic discectomy, Interlaminar endoscopic thoracic discectomy (IETD)/Thoracic endoscopic unilateral laminotomy for bilateral decompression and Retro-pleural Endoscopic transthoracic Discectomy.

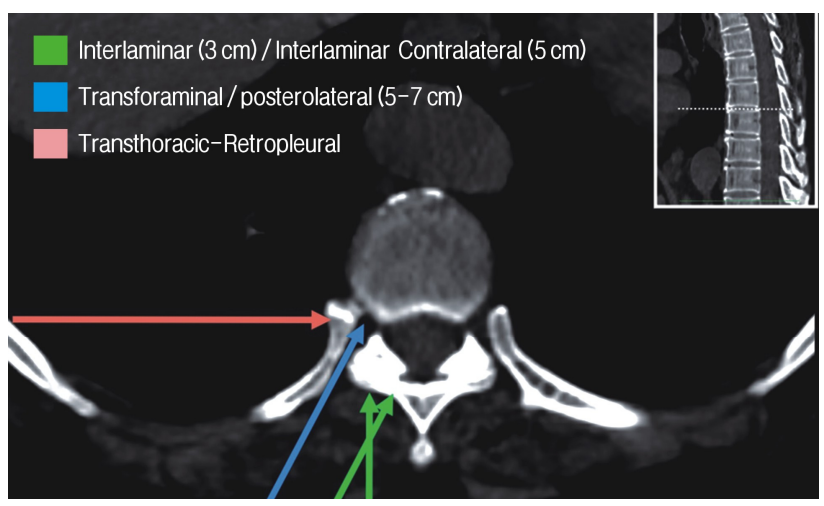

Figure 10. CT scan cut at thoracic disc level showing different approaches of FESS. TF approach needs partly removal of facet, pedicle and rib head. RETTD approach needs removal of head of rib articulating with two vertebra and then removal of ventral compression.
Transforaminal endoscopic thoracic discectomy (TETD) was first described by Choi et al. in 2010 for soft paracentral TDH and has been extensively used afterwards by many others ${ }^{56)}$. The procedure is performed under LA with conscious sedation. The procedure is conceptually like lumbar but the foramen in the thoracic spine is smaller, so obvious widening of the foramen is needed (Figure 11). The patient is positioned prone on a standard table or a Wilson frame. The entry point on the skin is determined from pre-operative Computed Tomographic (CT) or Magnetic resonance imaging (MRl) scans. A line is drawn from the mid-pedicular annulus extending to the lateral margin of the facet and then extended to the skin. It is usually $5-7 \mathrm{~cm}$ from the midline. An $18 \mathrm{G}$ needle is then advanced from this entry point and the tip is aimed at mid pedicular line on AP view and posterior vertebral line on the lateral view. The needle is kept parallel to the upper endplate of the lower vertebral body. After more LA infiltration, further process with sequential railroading is followed and reamers are used to shave off the ventral aspect of the superior facet. With burr the outer part of the superior facet is cut. Afterwards a bevelled working sheath is positioned. The disc is removed using endoscopic forceps. This approach provides good access in the lower thoracic spine, but the curvature of the ribs may prevent adequate tilting of the endoscope and is an important limitation in this regard. A flatter angle during access is thus facilitated by resection of bone at the facets to allow entry into the spinal canal or the foramen.

Interlaminar endoscopic thoracic discectomy (IETD) and Thoracic endoscopic unilateral laminotomy for bilateral decompression (TE-ULBD) ${ }^{161-163)}$. The use of the IL approach in the treat ment of TDH is technically difficult due to high risk of damage to the cord associated with it. The window is practically very

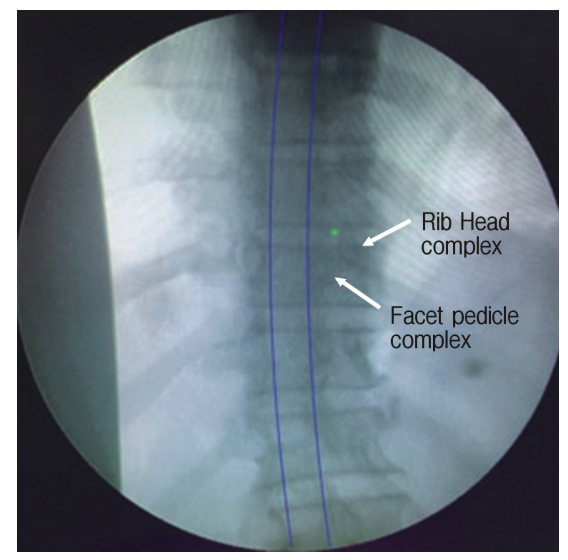

Figure 11. The left 30 degree Oblique view of the thoracic vertebrae. The green dot is the target entry point of the needle. Removal of part of facet and/or pedicle is needed for medialising the endoscope and coming near the medial and ventral area to cord (Blue Rail). The end-plate spur, annulus, disc fragment and calcifications can be removed. The noteworthy point is that the posterior surface of lumbar vertebral body is nearly straight but the thoracic vertebrae is concave and the cord is hugging and slightly encased into the vertebral body. It helps remove compressions without being horizontal in many cases. 
small and a significant amount of bone removal like medial pedicle resection is required to allow space for manipulation without damaging the cord. It should be used to remove only a dorsally dislocated DH which would be accessible through the IL window. However, its use in the treatment of posterior aetiologies without disc resection is possible with a stenoscope which may allow a controlled resection of posterior compressive structures. The procedure is similar to the one used in the lumbar spine. After prone positioning of the patient, incision is made about $3 \mathrm{~cm}$ or $5 \mathrm{~cm}$ from the midline (if contralateral decompression is required). The entry is enlarged with stepwise dilators and decompression is performed in the IL window using burr and Kerrison punches. When addressing bilateral pathologies, the ipsilateral side is decompressed first and then the contralateral side can be decompressed using an 'over the top' technique. The anterior pathologies may be addressed but require resection of facet and/or the medial pedicle if manipulation is needed. So, typically pathology lying ventral but lateral to myelon are better accessed through this approach. The anchoring method can be used to establish the working laminar passage when handling OPLL pathologies. Measuring the OPLL thickness on preoperative $C T$ scan helps. Here, a $\mathrm{K}$ wire can be first docked and after confirming level of surgery the endoscope is used directly and burred decompression is done or trephine created bone window is used to remove compression. The basic operating steps be summarized as thinning-separating-removing ${ }^{164)}$.

Retro-pleural Endoscopic transthoracic Discectomy (RETTD) ${ }^{162)}$ has been infrequently described previously. The patient is positioned right or left lateral depending on the type of aetiology. The surgeon stands at the anterior side of the patient. It is performed under GA and requires typical transthoracic approach anaesthesia protocols. A skin incision is made along the posterior edge of the vertebral body projection as marked fluoroscopically. After the incision the upper edge of the rib is located, the working canula and endoscope are inserted. The intercostal muscles are removed from the upper margin of the rib and the retropleural space is reached. Once the space is identified, blunt dissection usually with finger is carried out to identify the rib head in the target segment. The rib head is resected thus exposing the pedicle. After resection of the pedicle, the epidural space is reached from where the disc can be removed. So, the incision may be big as contradictory to stab incisions of FESS to start here but principle and advantage of FESS is fully applied ventrally (Figure 12).

FESS literature with respect to lower thoracic spine have progressed to its use in the upper and mid dorsal regions to ${ }^{165)}$. The initial use of these FESS were restricted to TDH but have been extended to include posterior stenosis, ossified LF, facet cysts, giant TDH and calcified TDH as well ${ }^{162)}$. Taking the individual situation into consideration, the FESS approaches used for the pathologies were: (1) IL approach for posterior pathologies: such as spinal canal stenosis, OLF, or cyst; DH dislocated posterior to dura or cranio-caudal sequestered $\mathrm{DH}$ lateral to the myelon; (2) TF approach for intra-/extraforaminal $\mathrm{DH}$, few medial intraspinal $\mathrm{DH}$, or possibly giant $\mathrm{DH}$; and (3) RETTD approach for medial DH or giant TDH or calcified TDH. But it can be used only up to about T-5 vertebral level due to anatomical restrictions. More cranial pathologies that cannot be decompressed using the TF approach must be surgically treated using conventional methods ${ }^{162)}$.

In the RETTD and TETD approaches, performing indirect boxshaped decompression before direct decompression is suggested for medial calcified pathology. In cases of bilateral ventral compressive pathology the resection over to the contralateral side has to be particularly done with care. In these cases the $25^{\circ}$ field of view provides false satisfaction of free anterior spinal cord and leading to a tendency of less contralateral decompression. In all techniques, free-floating dura mater in the irrigation fluid was evidence of sufficient decompression. Good visibility and pulsatile cord is enough to judge the decompression endpoint in all the three approaches ${ }^{162)}$.

Complications \& limitations: The peculiar location of thoracic pathologies in a narrow neuro-foraminal space makes complications an important part of the operative procedures. In a recent review of literature by Gibson et al, Dural tears were reported in $2 \%$ patients and transient paraesthesia or neuralgia in $2 \%$ patients, Revision surgery was required in 1.5\% patients, neurological injury was reported in $0.6 \%$ patients and epidural hematoma in $0.6 \%$ patients. Complications including vertebral insta bility, cerebrospinal fluid leak, pleural fistula, thoracic viscerainjury and intercostal neuralgia which are common with open surgeries were not reported in any of the papers on FESS approach to the thoracic spine ${ }^{1611}$.

Anatomic considerations and less frequent cases a surgeon sees in his lifetime are major limitations for this technique's evolution.

\section{iii) Cervical FESS}

Full endoscopic procedures have been reported in the cervical spine. Though the procedure is technically difficult but can be acquired by training. The learning curve is steep but the advantages of this procedure with a good outcome approaches to that of FESS surgeries in the other region. There are mainly four categories of FESS procedures that have been classified depending on the approach used and the type of aetiology addressed:

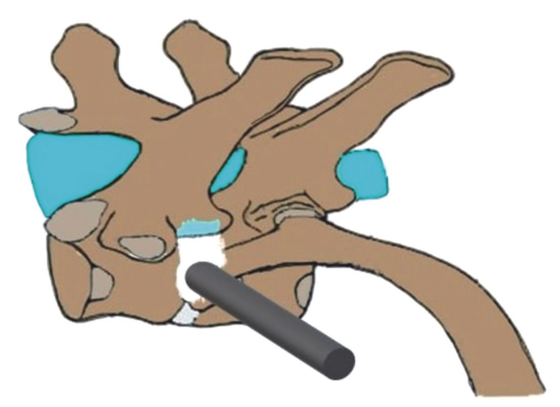

Figure 12. Transthoracic retro-pleural FESS. The approach does not open the pleural cavity and after resecting the head of the articulating rib, all ventral stenotic calcification can be excised without cord manipulation till the contralateral aspect. 
anterior endoscopic cervical discectomy (AECD), anterior endoscopic cervical trans-discal decompression (AETdCD), anterior endoscopic cervical trans-corporeal decompression (AETcCD), Posterior endoscopic cervical foraminotomy (PECF), Posterior endoscopic cervical discectomy (PECD) and cervical endoscopic unilateral laminotomy for bilateral decompression (CE-ULBD) ${ }^{166)}$. The gold standard treatment for cervical disc herniation and radiculopathy has been considered to be anterior cervical discectomy and fusion (ACDF) ${ }^{166)}$. This procedure provides removal of the offending pathology and offers good fusion rates. The use of full endoscopy procedures in cervical spine was earlier limited to the treatment of cervical disc prolapse and radiculopathies but now have included stenotic pathologies and myelopathy as well. Unlike in the lumbar spine there is a lack of highquality randomised control trials concerning with FESS in the cervical spine and the majority of literature is in the form of case series. Systematic reviews or meta-analysis are also lacking in this regard.

The choice of the endoscopic approach is determined based on the location of the primary pathology ${ }^{167)}$. When the main pathology is located anterior and medial to the lateral margin of the myelon anterior approach can be preferred in supine position. In contrast when the primary pathology is located posterior and lateral to the lateral margin of the myelon posterior approach is to be preferred (Figure 13) This rule applies to follow the basic fact that the spinal cord must not be retracted medially during the surgery. The anterior approach is more reserved for soft $\mathrm{CDH}$ since the size of the endoscope used is usually small as compared to posterior surgeries and allows limited working space. The anterior surgery is mainly effective for central and paracentral $\mathrm{DH}$. However, it can also be used for soft foraminal $\mathrm{DH}$ although

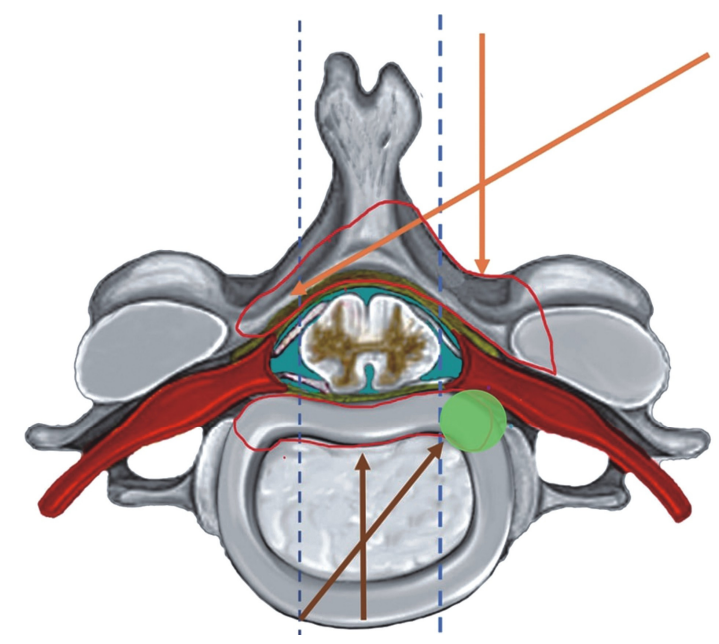

Figure 13. Posterior FESS Foraminotomy and discectomy are for pathology lateral to meylon only. Whereas anterior FESS can approach all pathology medial and lateral to melon. Dotted blue lines showing the extent of myelon. Area in red ventral to the myelon can be accessed by anterior route (Brown arrow). Area in red dorsal to the myelon can be accessed by posterior route (orange arrow). Area in green can be accessed by both anterior and posterior routes (brown and orange arrow). the approach for ipsilateral foraminal $\mathrm{DH}$ is better accessed through the contralateral side which provides a better trajectory ${ }^{167,168)}$. An important pre-requisite for using anterior approach is the height of the disc space that should be preserved to at least $4 \mathrm{~mm}$ to prevent secondary complications. Similarly, the craniocaudal extent of the herniation must not exceed more than half the distance of the vertebral body. Lastly in presence of bony foraminal stenosis a posterior approach is better suited for decompression. Much innovation has occurred in the posterior approach to cervical spine to improve approach related morbidity and provide outcomes comparable to open surgery and tubular assisted surgeries. Posterior FESS in the form of foraminotomy has provided an effective alternative for $\mathrm{DH}$ and stenosis which are exclusively lateral to the myelon ${ }^{27)}$. The stability is not affected by the surgery despite some amount of bony resection involved ${ }^{27,167)}$. The advantages of a posterior approach over an anterior one are minimized risk to the critical structures like trachea, oesophagus and carotid vessels. The difference between the endoscopes and the working channel stems from the fact that there is no restriction on the size of the endoscope based on disc height which is a common limitation in the anterior approach. This allows better visualization and the bony work performed is better.

Indications \& Contraindications: The classical indication for FESS procedures in the cervical spine is focal cervical radiculopathy due to cervical disc herniation $(\mathrm{CDH})$ or foraminal steno$\mathrm{sis}^{27,166,169)}$. The indications have gradually expanded to include cervical spondylotic myelopathy and cervical stenosis as well ${ }^{170,171)}$. But the studies have showed low reliability and doubtful results. Patients with calcified discs, severe compressive cervical myelopathy, cervical segmental instability and previous neck surgery are few contraindications. Severe obesity with a short neck is also a relative contraindication for anterior procedures ${ }^{27,168,169)}$.

Technique Anterior endoscopic cervical discectomy (AECD): Local or general anaesthesia is used with the patient in supine position. The anterior approach comprises mainly of the transdiscal route and the trans-corporeal route. Right side is usually preferred for central $\mathrm{DH}$ and contralateral approach for the paracentral $\mathrm{DH}$ which provides a better trajectory. The approach needle is advanced through a safe space created between the carotid sheath and the trachea by two fingers. The carotid artery is pushed laterally and the trachea medially with the help of index and middle finger of the left hand. This provides a safe space for the insertion of the spinal needle and it is targeted towards the disc space or the body depending upon the type of approach used (transdiscal vs transcorporeal). The transdiscal route is often associated with reduction of disc height after surgery, a minimum of $4 \mathrm{~mm}$ ventral height of the intervertebral space is a pre-requisite for the transdiscal approach ${ }^{27)}$.

In Anterior endoscopic transdiscal cervical discectomy (AETdCD) technique, the needle is passed through the deep cervical fascia and the anterior longitudinal ligament before entering the anterior annulus between the bilateral longus colli muscles ${ }^{167,168)}$. The palpation and developing finger tactile feedback is essential to prevent any complication. After radiological confirmation of the depth of the passage of the needle, a discography can be per- 
formed with contrast dye and indigo carmine. The needle is replaced by a puncture needle and working cannula is introduced at the point of $\mathrm{DH}$ after serial dilatation with a skin incision of 3-5 $\mathrm{mm}$. This dilatation prevents approach related pain and avoids soft tissue injury. Small diameter or lumbar endoscope is positioned. The irrigation of saline through the working channel is maintained at 30-40 ml/min which avoids dural irritation. Endoscopic vision allows identification of the dorsal annulus. Dorsal annulus and the posterior longitudinal ligament (PLL) are opened. The disc material is visualized and excised later after adequate annular release. Discectomy can be facilitated with the help of radiofrequency or laser. At the end of decompression, the dura can be visualized through the annular tear. Injury to anterior annulus should be minimized to prevent post-operative kyphosis.

In Anterior endoscopic trans-corporeal cervical discectomy $(A E T C C D)$ technique, a hole in the vertebral body is made instead of passage through the disc, this avoids injury to the disc space and prevents potential complications like disc collapse and postoperative kyphosis ${ }^{167,168,172)}$. This approach is particularly helpful for removal of migrated $\mathrm{CDH}$. This procedure requires significant bony work so is better performed under general anaesthesia. Once the spinal needle is fixed on the vertebral body it is advanced into the body till posterior margin of the target vertebra. The needle is then replaced with a blunt guide wire and a dilator is introduced to enlarge the hole. A working sheath is then introduced over the dilator and the bony tunnel is extended using a trephine (under fluoroscopy) or a high-speed burr (visualised). The PLL is then incised using endoscopic punches and the extruded disc material is visualized and removed. The final decompression is confirmed by visualisation, eyeballing of the fragment as per MRI measurement and through a blunt hook probing. Adequate haemostasis is ensured and a drain may be kept in the bony tunnel to avoid possibility of a hematoma. The surgeon can remove DH fragment or hypertrophied PLL as well. ${ }^{168,173,174)}$.

Technique: Posterior endoscopic cervical discectomy (PECD)/ Posterior endoscopic cervical foraminotomy (PECF) $)^{27,167)}$. The surgery is performed under GA or LA with the patient in prone position. GA is preferred because the posterior procedure involves significant bony work, and any patient movement should be avoided. Cervical fixation/traction on a Mayfield is preferred for allowing stability and more interlaminar space. The approach starts with localisation of the ' $Y$-point' at the lamino-facet junction. The $Y$ point comprises of the cranial lamina, caudal lamina and the facet joint. A needle is passed under fluoroscopic guidance and targeted towards the lamino-facet junction. An obturator is passed over the needle and soft tissue over the facet and lamina is dissected with special care not to enter the canal. A bevel ended working cannula is passed over the obturator with the bevel directed medially and the obturator is removed. This working cannula is used to introduce the working channel endoscope and bony structures are visualized afterwards. In PECD, the 25-degree optics coupled with continuous saline irrigation offers better visualization and ensuring better decompression. Further exposure of the bony landmarks and medial facet joint can be done with the help of radiofrequency coagulator and cutting forceps which help to remove overlying soft tissues. A diamond tipped burr is then used to resect the caudal part of the cranial lamina and the ligamentum flavum is exposed. Next, the bony resection is carried towards the medial half of the descending facet, the facet joint and the ascending facet. Furthermore, it is carried caudally towards the medial cervical pedicle and then towards the intersection of the caudal lamina with the ascending facet. This bony resection procedure is called foraminal unroofing and exposes the foramen well for the further soft tissue decompression. Once adequate unroofing is achieved, the ligamentum flavum is removed and the cervical nerve root is exposed with the underlying disc space. It is important to visualize the lateral border of the myelon for accurate anatomical localisation and to ensure adequate decompression. Excessive resection of the facet joint can be avoided by palpating the medial border of the cervical pedicle thus limiting the lateral extent of the foraminotomy and destabilization ${ }^{175)}$. Additional bony resection can be carried out with punches and burr to ensure that the exiting root is visualized laterally. Exploration of the disc space can be performed with the help of blunt dissector and hook by probing the axilla and shoulder of the nerve root. The extruded $\mathrm{DH}$ fragments may be removed using forceps and blunt dissector. Adequate decompression is indicated by free mobilization of the nerve root from its proximal part to the distal exiting zone. The posterior approach is simpler than anterior approach owing to absence of critical anatomic structures. However, the endoscopic orientation of cervical spine is unfamiliar with most surgeons and there is a steep learning curve for this procedure. It is desirable to familiarise oneself with the anatomic structure and acquire technical dexterity with lumbar endoscopic techniques before moving to cervical spine. It is of paramount importance to correctly localise the lamino-facet junction during the surgery and to keep bony resection of the facet to less than $50 \%$ to avoid instability.

Technique: Cervical endoscopic unilateral laminotomy for bilateral decompression (CE-ULBD) ${ }^{172,176,177)}$. The initial target of the approach is medial aspect of the ipsilateral pedicle for needle and dilators. Dissection of the surrounding soft tissues is performed. At the docking site the working cannula is inserted over the dilator. The endoscope with cautious radiofrequency and micropunches are used to remove tissue and visualize the adjoining edges of lamina. The diamond burr is used for visualising laminotomy along with the insertion of the LF. After optimal bone work, the LF is resected with micro-punches and Kerrison rongeurs. The visualization of thecal sac margin confirms the ipsilateral decompression. Angulation is increased and undercutting the midline spinous process base is done. Next, the contralateral, over-the-top decompression is completed. Free mobilization and pulsation of the thecal sac are the end point of decompression.

Complications \& Limitations: The most commonly reported complications in endoscopic procedures were dural tear (4.65\%) transient hypesthesia (3.37-4.65\% and transient dysphagia (1.96$3.70 \%)^{172,178)}$. In anterior PECD there is a risk of injury to the trachea, oesophagus, major vessels and the spinal cord. There is risk of incomplete removal of $\mathrm{DH}$ and re-herniation. The overall complications are usually higher in the trans-corporeal route as compared to trans-discal route ${ }^{168)}$. The recurrence rates may 
range from $3-5 \%$ cases in the anterior approach ${ }^{168,169)}$. There is a risk of end plate collapse after the trans-corporeal route and should be monitored during post-operative evaluation. The bony tunnel made in the transcorporeal route is thought heal spontaneously with time and does not pose additional problems ${ }^{168)}$. In posterior PECD, there is a risk of injury to the nerve root or the myelon. Excessive resection of the facet may lead to post-operative instability. There is also a risk of haemorrhage from the epidural venous plexus and if not controlled well, it may hinder visualisation and require conversion to an open procedure. Hence, use of radiofrequency coagulator and other haemostatic agents becomes important. Similarly, long standing $\mathrm{DH}$ may lead to adhesions. Careless dissection may lead to dural injuries and may require conversion to open for repair of the injured dura. Transient dermatome related hypesthesia has also been reported. Infections, spondylodiscitis or thrombosis although rare have been reported. Recurrence is reported in around $3.4 \%$ cases in a recent RCT by Ruetten et $\mathrm{al}^{27)}$. The effects of saline irrigation and unrecognized dural injury intra-operatively exists and needs evaluation.

Advances: Although calcified discs are difficult to address under the endoscope, a recent report of posterior transpedicular endoscopic access to calcified focal stenosis has reported good results ${ }^{171)}$. Osseous stenosis was earlier a relative contraindication for full endoscopy, but few surgeons have reported good results with these too ${ }^{170)}$. Similarly, there have been reports of all endoscopic fusion through an anterior approach which holds promising future in this regard ${ }^{179)}$. The use of cervical endoscopy in spondylotic myelopathy was also a contraindication earlier but recent articles have reported clinical improvements by endoscopic treatment to be comparable to open surgeries ${ }^{31,176,177)}$.

Acute or progressive myelopathy at craniovertebral junction needs odontoidectomy by trans nasal or transoral route, which have been reported by endoscopy also (RECD). But, the chances infection are there. The FESS uniportal retropharyngeal approach is feasible and gives excellent alternative and a feasible good option in retro-dental pannus, infection at Craniovertebral junction or basilar invagination ${ }^{180-182)}$.

\section{iv) Sacral FESS: Trans-sacral Epiduroscopic Lumbar Decompression (SELD)}

SELD allows epiduroscopic access through the sacral hiatus and facilitates visualisation and treatment of a wide variety of epidurally located lesions. Currently it is done with steerable flexible epiduroscopic system. The indications for this procedure have been ever increasing and most authors believe SELD to be an effective alternative for percutaneous epidural neuroplasty (PEN) ${ }^{183}$.

The underlying concept is of decompression via ablation changing protein structure ${ }^{184-186)}$. PEN uses epidural application of hypertonic saline for epidural adhesiolysis through different epidural approaches.

Indications \& Contraindications: SELD is most commonly used in the treatment of discogenic low back pain and radicular pain attributed to HNP. Central and paracentrally located herniations are classical indications. Similarly presence of discal cysts, HIZ and fibrosis around the nerve fibres are also indications for SELD ${ }^{187-189)}$.
Mild to moderate soft disc herniation is the optimal indication for this procedure ${ }^{188,190)}$. Advantage in the treatment of central $\mathrm{LDH}$ particularly at L5-S1 is obvious.

Profound motor weakness, CES, hard disc herniations, lateral and foraminal disc herniations, instability, known haemorrhagic disorders and anatomic abnormalities of the sacral hiatus are known contraindications ${ }^{189)}$. Severe stenosis remains a contraindication. Also presence of infections, spondylolisthesis and significant psychological disorders are also contraindications for SELD ${ }^{188)}$.

Technique: The procedure is performed in the prone position under local anaesthesia and sedation. It is done under fluoroscopy. A $3-5 \mathrm{~mm}$ skin incision is made over the sacral hiatus. A puncture is made in the sacrococcygeal ligament using a trocar. It is advanced to S2-3 level it is followed by a guide wire and a dilator. This is followed by introduction of a video guided catheter (VGC) into the ventral epidural space. It is advanced to targeted disc. Next, an endoscope $(1.2 \mathrm{~mm})$ is inserted through one of the two portals in the VGC to visualise the epidural space. The other portal is used to advance a Ho:YAG laser. An epidurography is performed through a side tube of the catheter by injection of contrast and confirming anterior epidural catheter, and also showing outline of LDH or adhesions. A hole is created in the posterior longitudinal ligament (PLL) by laser cauterisation with variable power. Any sequestrated fragments can be removed with a $1 \mathrm{~mm}$ forceps. Repeat epidurogram is performed to confirm a free flow of dye. Physiological saline is constantly irrigated.

Complications \& Limitations: Some limitations arise due to the technical problems (images acquired during the procedure are of low quality as are the equipments) associated with SELD. Secondly laser induced damage to the posterior annulus may lead to recurrent herniations ${ }^{191)}$. The cost of the equipments is also a limitation. There is a risk of infection leading to meningitis, epidural abscess and cauda equina syndrome ${ }^{192,193)}$. Continuous irrigation may contribute towards a raised intracranial pressure (ICP) and development of headache, nausea and vomiting. Vision changes in patients of glaucoma may be catastrophic. Caution is to keep saline use to no more than $100-350 \mathrm{ml}^{1844}$. Neurological deficits may develop like foot drop and cauda equina syndrome $(C E S)^{192,194,195)}$. Other complications may include POD, incomplete decompression, subchondral osteonecrosis, epidural hepatoma, and dural tears ${ }^{196-201)}$. SELD is still an emerging concept and there is a lack of clearly established guidelines, outcome data and complications are infrequently reported. It does not form the first line of treatment in $\mathrm{LDH}$.

Advances: Recently the indications for SELD have expanded to even discal cysts, treatment of migrated LDH and up to moderate canal stenosis as well ${ }^{188,198)}$. More improvements are expected with the advancement of quality of the fibre-optic camera and quality of mechanical/flexible instruments.

\section{DISCUSSION}

\section{A. General Literature}

Given the general notion that minimally invasive surgery would be associated with less muscle injury than open surgery could 
not been proven ${ }^{52}$. The most basic concept of FESS is minimalistic approach and achieving curative effectiveness of the spinal pathologies as equivalent or better than open surgeries. This reduces morbidity, complications and the recovery time significantly. The approach is based on percutaneous small window surgery and provides far better visualisation than microscopes ${ }^{5)}$. It avoids or reduces the non-essential extensive lamina/facet resection or neural retraction especially with transforaminal approach. Local or regional anaesthesia, especially for the elderly or medically morbid patients is an additional boon ${ }^{39,48,49,51)}$.

The rate of common perioperative complications such as hematoma, dorsal dural tear, and surgical site infection are too low. There are unique complications such as a ventral dural tear, injury to the exiting nerve root, instrument breakage, seizures and increased radiation exposure ${ }^{94,202-206)}$. The learning curve is quite steep for foraminal approach and flatter for interlaminar approach $^{114,189,207-209)}$. Systematic training in ESS techniques and anatomical knowledge are canty at university and spine organisation levels which are dominated by conventional teachers. Contraindications and advanced indications should be avoided early in endoscopy career. The commonest causes of failed ESS are either complications or incomplete decompression ${ }^{198,210,211)}$. Careful patient selection is needed. Profound painless motor weakness is usually contraindicated ${ }^{5}$. In the case of a conjoined nerve root in the neural foramen, a transforaminal approach should be avoided. Technique based on pioneer classifications for approach selection will aid for beginners. Success of ESS would depend upon a is precise surgical technique. We can encounter inaccessible location or disease pathology. For those cases, modifications and improvisation to the technique may be required for avoiding complications and achieving effective decompression. The target landing point should be nearest to the pathology. The endpoints of the decompression procedure of the neural sacs and sleeve should be ensured. Majority of endoscopic experts have put their view for performing customized surgery for the patients rather than pushing only one technique to achieve desired results ${ }^{68)}$.Virtual reality, augmented reality, and mixed reality surgical simulators in endoscopic surgery demonstrate improvement in technical skill and patient outcomes and may revolutionise the future of these sugeries ${ }^{212)}$. Classification based approach for deciding the type of surgery also have been reported in the literature and are useful for at least beginners $^{30,213,214)}$

\section{B. Technique Specific Literature Review}

\section{(1) TELD/TELF/TE-LRD/TELVD}

The only RCT that compared transforaminal or inter-laminar endoscopy with microdiscectomy and proving better quality outcomes of percutaneous procedure, was doubted for its randomisation, but still was an eye opener ${ }^{51)}$. In 2010, with one randomized controlled trial, 7 non-randomized controlled trials and 31 observational studies identified on TELD for LDH, failed to elicit a statistically significant difference in leg pain, overall improvement, recurrence and complication with the OD group ${ }^{52)}$. In one of the
Cochrane Review, MD/ MLD/OD with a MID (percutaneous endoscopic interlaminar or transforaminal lumbar discectomy, transmuscular tubular microdiscectomy and automated percutaneous lumbar discectomy), 11 studies were identified. In this heterogenous study, low-quality evidence suggested that MID may be inferior in terms of relief of leg pain, low back pain and re-hospitalisation ${ }^{215)}$.

Another systematic review and meta-analysis noted no significant differences in rates of complication or re-operation between approaches, and was published around the same time ${ }^{216)}$. A greater revision rate after TELD in some studies was offset by more rapid patient recovery ${ }^{2)}$. In one of the RCT with a total of 153 participants randomly assigned (TELD vs MED), TELD did not show superior clinical outcomes and did not seem to be a safer procedure for patients with LDH when compared with MED. TELD had inferior results for central disc herniation. POD was common in the MLD group. But follow up rate was only $89.5 \%$ for TELD ${ }^{217)}$.

TELD technique has been authenticated by most of the randomized trials ${ }^{48-51,218,219)}$. The most recent systematic review and meta-analysis including 26 studies ( 5 of which being randomized controlled trials), found that while open and tubular MLD appear equivalent in terms of clinical outcome and safety, TELD was associated with significant improvements in blood loss, markers of inflammation, durotomy incidence, patient-reported clinical outcome measures, length of hospital stay (LOS), and time to resume work ${ }^{220)}$. Most of the systematic reviews and meta-analysis have proven that the TELD is not inferior to those of standard $\mathrm{OD} / \mathrm{MLD}$ and gives efficacious success rates with acceptable complication rates and recovery time ${ }^{53,54)} . \mathrm{IO}, \mathrm{OE}$ and $\mathrm{FEE}$, all techniques provide favourable comparable outcomes in the management of $\mathrm{LDH}^{59,61)}$.

High quality reports have now boomed in the last demi-decade $^{218,221-225)}$. A multi-centre, non-inferiority randomized controlled trial, including 682 patients with over 2 years follow up to evaluate the efficacy and cost-effectiveness of PTELD compared to $\mathrm{OD}$ is currently underway ${ }^{26)}$.

\section{(2) IELD/IE-LRD/ICELF}

Choi et al, (2005) in a study of IELD on 67 patients under local anaesthesia succeeded in 65 patients ( 2 patients had to be converted to open surgery) and further stated that it is a safe alternative approach for LDH and clinical efficacy is comparable with other techniques. The mean LOS was 12 hours. Successful outcome was reported in $90.8 \%$ patients, while there were complications $(18.5 \%$.) like two cases of dural injury, nine patients suffered from $P O D$, one patient had recurrence (managed with OD), two patients had residual back pain and two had leg pain ${ }^{26)}$.

Ruetten et al reported feasibility in 372 patients suffering from LDH managed with IELD. He reported a recurrence rate of 2.4\% without tneurological complications. On 331 patients followed for 2 years, $82 \%$ reported having no leg pain, and 13\% had only occasional pain. All the 29 patients (9\%) with poor results had additional back pain. Five of the patients had previously undergone conventional surgery at the same level, the other 24 were found intraoperatively to have only hard tissue and epidural adhesions instead of soft disc prolapse. It was concluded that $\mathrm{LDH}$ can be 
treated effectively with this technique but further technical advancements are required for satisfactory resection of the hard tissues which at that time was not achievable due to the smaller size of the endoscope ${ }^{139)}$. Another report by Ruetten et al. comparing total of 161 patients with IELD or MLD showed that $74.5 \%$ of patients reported no longer having leg pain, and $20.5 \%$ had only occasional pain. The clinical results were the same in both groups. But, the rate of complications and revisions were reduced significantly in the IELD group ${ }^{143)}$. The indication of IL FESS are evolving and in revision discectomy, one can encounter significant scar tissue. However, blunt dissection, can safely be done to perform a safe discectomy ${ }^{227,228)}$.

A retrospective study of 479 cases (4 patients lost to follow up, higher segment, extraforaminal or recurrent LDH excluded) with a mean follow- up time of 44.3 months showed favourable outcomes threw great light on the learning and complications associated with the procedure. Twenty-nine (6.0\%) complications including 3 cases $(0.6 \%)$ of incomplete decompression in which the symptoms gradually decreased by conservative methods, 2 cases $(0.4 \%)$ of nerve root injury which recovered in 1-3 months, 15 cases (3.1\%) of paraesthesia, and 9 cases of recurrent herniation (1.9\%) were noted. No dural tears were reported. Furthermore, the complication rate for the first 100 cases was $18 \%$. This rate decreased to $2.9 \%$ for in the later cases. The complication rate for the L4-5 herniations (8.2\%) was greater than that for the L5-S1 herniations $(4.5 \%)^{229)}$.

Further Ruetten et al reported that IELD provided better results than MLD due to better visualization. If any hindrance is encountered switch to standard open procedure. Their results demonstrated that the complication rate of the full-endoscopic group (10.9\%) was significantly lower than that of the microsurgical group $(19.5 \%)^{51)}$. A recent meta-analysis which searched six common databases, included Nine studies involving 621 patients (TF:297/IL:324) of L5-S1 LDH. The analysis couldn't identify any significant difference in functional outcome parameters (VAS, JOA score, Macnab score), estimated blood loss, bed time after surgery or LOS when comparing TELD and IELD. However, a significantly lower incidence rate of dural tear was observed in TELD compared with IELD group. On the contrary IELD was superior to TELD regarding fluoroscopy time and operative time, suggesting better outcomes for L5/S1 $\mathrm{LDH}^{230}$ ) . Lee et al. indicated that the central LDH with high canal compromise and highgrade herniations showed a high rate of incomplete decompression treated with IELD ${ }^{75)}$. However complete removal of the highly migrated disc material by IL route was confirmed with MRI in 16 patients (success rate 89\%) ${ }^{231}$. Another meta-analysis of Si Yin et al, observed that TELD was associated with a certain rate of recurrence (3.6\%). The incidence of early recurrence was nearly double than the late recurrence rate. The recurrence estimates after IELD and TELD were $4.2 \%$ and $3.4 \%$ respectively ${ }^{232)}$. The POD, nerve root injury, surgical site wound complications, recurrence, conversion to open surgery, incomplete decompression, and total complication rate did not differ significantly between TELD and IELD in the treatment of lumbar disc herniation ${ }^{233)}$.

Nerve root injury is still a common complication of FESS ${ }^{76,234,235)}$.
The incidence of POD among the patients with lateral recess stenosis (4 cases, 27\%) was significantly greater than those without lateral recess stenosis in IE-LRD ${ }^{229)}$. In a feasibility study with a total of 120 patients (aged 60-85 years) diagnosed with L5-S1 disc herniation were compared for outcomes in LA and GA in IE-LRD. Patients in both LA and GA groups had comparable VAS grade, ODI functional outcome improvement after operation. However, POCD (postoperative cognitive dysfunction) developed only in GA group. In addition, LA group had no bed confinement, shorter hospital stay, and lower cost. Moreover, a willingness to receive procedure again if needed under LA was noted $^{236)}$. Biomechanics and the stability of lumbar spine changes partly after $1 / 4$ resection of the SAP and more obvious instability when $2 / 4$ is resected ${ }^{237)}$. IELD provides minimal injury to collateral soft tissue and enhances post-surgery recovery ${ }^{26,238)}$. Both young and athletic as well as elderly, obese and multimorbid patients experience significant benefits. The small skin incision, constant saline irrigation as well as the avoidance of retractor systems reduces wound healing problems or infection rates ${ }^{239}$. However, a hard to master lengthy learning curve to acquire the surgical skills, is considered as one of the draw backs of the technique ${ }^{114,240)}$.

\section{(3) Thoracic FESS}

Most authors have reported good outcomes on their FESS approaches in the thoracic spine. In one of the largest series reported by Bae et al on 92 patients undergoing full endoscopic surgery of the thoracic spine, they reported excellent or good outcomes(Modified Macnab's criteria) in 90\% patients ${ }^{159)}$. Complications were reported in 6.5\% patients out of which 2 had recurrent disc herniation. Similarly, in another series by Lee et al in a series of 87 patients, they have reported $71 \%$ reduction in VAS score for back pain and 69\% reduction in ODI scores ${ }^{241)}$. Complications were found in 5.7\% patients which included recurrence of TDH and recovered paraesthesia. In another series by Ruetten et al on 55 patients, they have reported $77 \%$ reduction in VAS score for back pain and 55\% improvement in VAS scores for leg pain ${ }^{162)}$. With 18 (TETD), 25 (IETD), 8 (RETTD) approach cases the rate of all complications was total $19 \%$, and that of serious complications was 5.8\% (1 epidural hematoma with revision, 1 temporary deterioration of myelopathy for 5 weeks, and 1 persistent deterioration of myelopathy). This is lower than the rate reported in the literature ${ }^{162)}$. Thirteen patients of OPLL treated with optimal resection of isolated ossified lesion by TE-ULBD. The preoperative and final follow-up cross-sectional area of the stenotic dural sac was $47.87 \pm 8.98 \mathrm{~mm}^{2}$ and $130.47 \pm 19.07$ $\mathrm{mm}^{2}$, respectively even with only ipsilateral approach. The modified Japanese Orthopaedic Association score and Visual Analog Scale scores improved significantly ${ }^{164)}$. Sixteen patients of myelopathy due to ventral compression (5 soft $\mathrm{DH}, 7$ calcified $\mathrm{DH}$ and 4 osteophyte spurs) operated through TETVD showed remarkable improvement without major complications. Two cases reported intercostal neuralgia ${ }^{242)}$. In a study of Fourteen patients with thoracic OLF (4 combined with dural ossification) IL approach underwent FESS was performed. The space between the ossification and the spinal cord is where canal access is to start, then 
the dorsal and contralateral decompression was performed with the "Over the Top" technique. Neurological function improved without any serious complications. Dural tears occurred in 5 patients, intraoperative neurological deterioration occurred in 1 patient, and intraoperative headache and neck pain occurred in 1 patient ${ }^{243)}$. In a study of thirty single-segment OLF patients, neurological status improved from a preoperative $\mathrm{mJOA}$ score of $6.0 \pm 1.3$ to a postoperative mJOA score of $8.5 \pm 2.0(p<0.001)$ at an average follow-up of 21.3 months. The average RR was $53.8 \%$. Dural tears in two patients $(6.7 \%, 2 / 30)$ were the only observed complications ${ }^{163)}$. Fifteen cases of OPLL in another study operated by TEIVD has shown 71.4\% improvement of Macnab's score with JOA and ODI improvements. No serious complications were noted ${ }^{244)}$. Another study with Ninety-two patients who underwent TETD for TDH, all patients showed a significant improvement of pain. There was one patient who had transient motor weakness ${ }^{152)}$. The overall trend of results varies from $46-100 \%$ for excellent and good outcome. This provides promising future in the treat- ment of thoracic spine pathologies ${ }^{163,242,245-247)}$.

Overall, there are no clear standards in the literature as of now with respect to the surgical approach to be chosen. Though certain recommendations have been made, the surgical technique must be determined for every pathology on a case-by-case basis. If equal suitability of the TETD and the RETTD approaches is noted, the TETD approach is to be preferred. The larger, more medial, or more calcified the disc herniation would allow a more likely use transthoracic approach ${ }^{162)}$.

\section{(4) Cervical FESS}

In a study of outcomes of discectomy by endoscopic transdiscal vs transcorporeal route, Ren et al have reported no significant difference between both the approaches. The trans-corporeal route offered lower recurrence and rate of disc collapse but the operative time and rate of end plate collapse were higher ${ }^{168)}$. They also postulated that when the tunnel diameter in the transcorporeal route was limited to $6 \mathrm{~mm}$ and the bony defect can heal without collapse of superior end plate. Similarly, in a paper by Ruetten et al on 120 patients of cervical soft $\mathrm{DH}$, they have compared $A E C D$ vs conventional ACDF, they observed no difference in the clinical outcomes between both the groups and at the same time FESS approach offered lesser operative time, blood loss and rapid rehabilitation ${ }^{169}$. The rate of complications and revisions were not statistically different in either of the groups. Ruetten et al have also compared the results of FESS, PECD with $A C D F$ in a prospective randomised control study, they have concluded that posterior PECD offered similar clinical results to the conventional groups and at the same time provided lesser tissue trauma, better mobility and other advantages of a minimally invasive technique ${ }^{27)}$. In majority of studies published on PECD there is good to excellent relief of radiculopathy comparable to open procedures ${ }^{27,248,249)}$. In a randomised control trial (RCT) published by Ruetten et al on the comparison of outcome between PECD and standard open ACDF for soft cervical DH, they have found no significant differences in the clinical outcomes and complication rates in both the groups ${ }^{27)}$.

\section{(5) Sacral FESS}

In one of the early series described by Ruetten et al. about the epiduroscopy guided interventions on 93 patients, 45.9\% patients reported positive results post procedure ${ }^{24)}$. These patients were grouped in back-leg pain syndrome and epiduroscopic adhesiolysis was performed in them. Similarly, a series of 300 patients were reported by Graziotti and a series of 250 patients were reported by Lee et al. subsequently ${ }^{187,188)}$. Lee et al included 250 patients of low back pain and radiculopathy who were treated by SELD and reported reduction in VAS scores for leg pain from a pre procedure value of 7.1 to 3.6 two weeks after the procedure ${ }^{188)}$. Similarly, the VAS score reduced to a 2.6 at 3 months. The Oswestry Disability Index (ODI) improved from 50 to 19 at two weeks and 12 at 3 months respectively. They reported a $5.8 \%$ recurrence rate and complications in $4.4 \%$ cases. In a recent series by Son et al, on 82 patients who were enrolled in the study, the success rate (excellent or good) as per Odom's criteria at 6 months was found to be $58.5 \%$. The reported rate
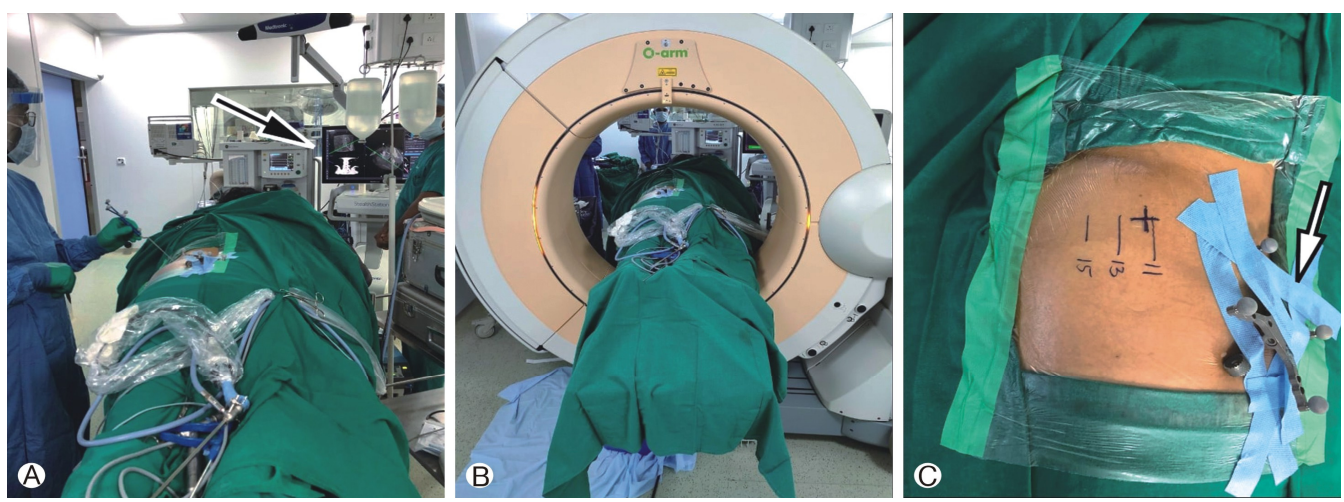

Figure 14. (A), (B): The author AK Navigating with Medtronic-O-Arm low dose CT acquisition. Navigated projected images (Black Arrow) helps decide the trajectory, length and hinderance if any (facet, transverse process or iliac crest specially in L5S1 level (C): Digital Reference Frame Stick to skin (Arrow), with markings done supra iliac in this index case. 
of complications was $8.5 \%$ and they concluded SELD achieved less favourable patient satisfaction as compared with previous studies ${ }^{190)}$. Ito et al have reported their use of SELD in the treat ment of discogenic low back pain by ablation of HIZs. In their series of 52 cases, the VAS score for low back pain improved from 5.6 to 2.2 at one month after procedure and further to 1.2 at 12 months. The ODI reportedly dropped from 22.3 to 8.8 at 12 months after the procedure ${ }^{192)}$. In a comparison of outcomes between patients treated by SELD vs microscopic lumbar discectomy, Kim et al found that the clinical outcomes in both the groups were comparable in terms of pain control, However, time to return to work was significantly lower in the SELD group. On the other hand, the rate of radiological operative failure due to incomplete decompression was present in $30 \%$ patients of the SELD group as compared to $0 \%$ in the other group ${ }^{198)}$. Similarly, recurrent disc herniations were also higher in the SELD group. In a study by Ülgen et al on 163 cases treated by epiduroscopic laser discectomy, 92.02\% patients reported relief of pain and significant reduction in VAS and ODI scores ${ }^{194)}$.

\section{Futuristic Applications}

Ultrasound (US) guided TELD is a new method to reduce the radiation dose during puncture and cannulation, also for radiation safety against cancers and infertility, it is definitely a better tool. This method is the only one that gives the real time guidance while inserting the needle. Thus it avoids the threat of causing injuries. Moreover, the US guidance allows the surgeon to visualize each step, allowing to give exacting control of movement near the foramen and nerve root ${ }^{250)}$. Ultrasonic osteotome device is an oscillating device without lateral vibrations. So the tip does not injure sensitive tissue like spinal cord or nerve root even if the tip touches them unlike a burr system which is based on rotating movements. In addition the system is relatively easy for beginners and can compensate the area for the lack of technical expertise ${ }^{251)}$. This system is a game changer in open surgeries and will be equally effective in FESS too ${ }^{152,252)}$, XMRI (intraoperative MR scan) alleviates major concern with FESS i.e. the risk that revision surgery will be required due to the possibility of remnant $\mathrm{DH}$ fragments. Post-surgery the patient (without changing the operating position) can be shifted to an XMR to check for the adequacy of the decompression. This would reduce the need for a separate, second surgery and increasing the success rate of FESS ${ }^{253)}$.

Navigation is another development in spine surgery and FESS (Figure 14). It will enhance the surgeon's ease of learning and performing TELD and likely save radiation years of surgeon ${ }^{209)}$. This will likely get replicated in other FESS as well. The iso-centric navigation technique is practical and effective in reducing puncture times among difficult puncture cases which may be useful especially at the L5/S1 level ${ }^{254)}$. However, this carries with itself a unique set of difficulties, now the surgeon has to shuffle eyesfrom the C-arm or navigation monitor, endoscopy monitor, and surgical site, despite having a near perfect entry and landing points. Therefore, creating a navigation system with integrated smart glasses and augmented reality, could be an innovative technology with huge ergonomic benefits as well ${ }^{9)}$.

\section{CONCLUSION}

The techniques and indications of FESS has evolved. The scientific evidence has moved away from inferiority to non-inferiority when comparing results with conventional techniques. Its superiority in all aspects would soon get established and is likely to be the future of spine surgery with further innovations in technology and learnings.

\section{CONFLICT OF INTEREST}

Dr. A Krishnan is an editorial board member of the journal but was not involved in the peer reviewer selection, evaluation, or decision process of this article. There are no other potential conflicts of interest relevant to this article to declare.

\section{REFERENCES}

1. Liounakos JI, Wang MY: The Endoscopic Approach to Lumbar Discectomy, Fusion, and Enhanced Recovery: A Review. Glob Spine J 10(2 Suppl):65S-69S, 2020

2. Middleton SD, Wagner R, Gibson JNA: Multi-level spine endoscopy: A review of available evidence and case report. EFORT Open Rev 2(7):317-23, 2017

3. Choi G, Pophale CS, Patel B, Uniyal P: Endoscopic spine surgery. J Korean Neurosurg Soc 60(5):485-497, 2017

4. Chung AS, McKnight B, Wang JC: Scientific View on Endoscopic Spine Surgery: Can Spinal Endoscopy Become a Mainstream Surgical Tool? World Neurosurg [Internet] 145:708-711, 2021 Available from: https://doi.org/10.1016/j.wneu.2020.05.238

5. Ahn Y: Current techniques of endoscopic decompression in spine surgery. Ann Transl Med 7(S5):S169, 2019

6. Ruetten S, Komp M, Godolias G: An extreme lateral access for the surgery of lumbar disc herniations inside the spinal canal using the full-endoscopic uniportal transforaminal approach-technique and prospective results of 463 patients. Spine (Phila $\mathrm{Pa} 1976$ ) 30(22):2570-2578, 2005

7. Kim H-S, Sharma S, Wu P, Raorane H, Adsul N, Singh R, et al.: Complications and limitations of endoscopic spine surgery and percutaneous instrumentation. Indian Spine J 3(1):78, 2020

8. Krishnan A, Barot MP, Dave BR, Bang P, Devanand D: Percutaneous transforaminal endoscopic decompression and cageless percutaneous bone graft transforaminal lumbar interbody fusion: A feasibility study. J Orthop Allied Sci 6(3):21-27, 2018

9. Akbary K, Kim JS: Recent Technical Advancements of Endoscopic Spine Surgery with Disparate or Disruptive Technologies and Patents. World Neurosurg 145:693-701, 2021

10. Oppenheim H KF: On entrapment or strangulation of the cauda equina. DMW-German Med Wkly 35(16):697-700, 1909

11. Middleton GS TJ. Injury of the spinal cord due to rupture of an intervertebral disc during muscular effort. Glasgow Med J LXXV 76(1):1-6, 1911

12. Burmann MS: Arthroscopy or the direct visualisation of joints. J Bone Jt Surg 13:669-695, 1931

13. Leu H: Percutaneous techniques: Decompression and intradiscal 
laser in discoscopy, external pedicular fixation, percutaneous interbody fusion, peridural endoscopy with discoscopy. $12^{\text {th }}$ Course Percutaneous Endosc Spinal Surg 1993

14. Mixter WJ, Barr JS: Rupture of the Intervertebral Disc with Involvement of the Spinal Canal. New Engl Surg Soc 211(5):210215, 1934

15. Love JG: Removal of the protruded intervertebral discs without laminectomy. Mayo Clin Proc 14:1800, 1939

16. Kambin P BM: Percutaneous posterolateral discectomy. Anatomy and mechanism. Clin Orthop Relat Res 223:145-154, 1987

17. Yasargil MG: Microsurgical Operation of Herniated Lumbar Disc 1977

18. Caspar W: A New Surgical Procedure for Lumbar Disc Herniation Causing Less Tissue Damage Through a Microsurgical Approach 1977

19. Williams RW: Microlumbar discectomy: A conservative surgical approach to the virgin herniated lumbar disc. Spine (Phila Pa 1976) [Internet]. Jun 1 [cited 2021 Jan 31];3(2):175-182, 1978 Available from: https://europepmc.org/article/med/663769

20. Forst R, Hausmann B. Nucleoscopy - A New examination technique. Arch Orthop Trauma Surg 101(3):219-221, 1983

21. Schreiber A, Suezawa YO LH. Does percutaneous nucleotomy with discoscopy replace conventional discectomy? Eight years of experience and results in treatment of herniated lumbar disc. Clin Orthop Relat Res 238:35-42, 1989

22. Foley KT, Smith MM, Rampersaud YR: Microendoscopic approach to far-lateral lumbar disc herniation. Neurosurg Focus 7(5): E5, 1999

23. Fessler RG, Khoo LT: Minimally invasive cervical microendos copic foraminotomy: An initial clinical experience. Neurosurgery 51(Suppl 5):37-45, 2002

24. Ruetten S, Meyer O, Godolias G: Application of holmium: YAG laser in epiduroscopy: Extended practicabilities in the treatment of chronic back pain syndrome. J Cin Laser Med Surg 20(4):203206, 2002

25. Schubert M, Hoogland T: Endoscopic transforaminal nucleotomy with foraminoplasty for lumbar disk herniation. Oper Orthop Traumatol 17(6):641-661, 2005

26. Choi G, Lee SH, Raiturker PP, Lee S, Chae YS: Percutaneous endoscopic interlaminar discectomy for intracanalicular disc herniations at L5-S1 using a rigid working channel endoscope. Neurosurgery 58(Suppl 1):59-68, 2006

27. Ruetten S, Komp M, Merk H, Godolias G: Full-endoscopic cervical posterior foraminotomy for the operation of lateral disc herniations using 5.9-mm endoscopes: A prospective, randomized, controlled study. Spine (Phila Pa 1976) 33(9):940-948, 2008

28. Yeung AT Gore S: Evolving methodology in treating discogenic back pain by Selective Endoscopic Discectomy (SED) and thermal annuloplasty. J Minim Invasive Spinal Tech 1:8-16, 2001

29. Gore S, Yeung A: The "inside out" transforaminal technique to treat lumbar spinal pain in an awake and aware patient under local anesthesia: Results and a review of the literature. Int J Spine Surg 8:28, 2014 Available from: http://dx.doi.org/10.14444/ 1028

30. Lewandrowski KU: "Outside-in” technique, clinical results, and indications with transforaminal lumbar endoscopic surgery: A retrospective study on 220 patients on applied radiographic classification of foraminal spinal stenosis. Int J Spine Surg 8:26, 2014
Available from: http://dx.doi.org/10.14444/1026

31. Yuan H, Zhang X, Zhang LM, Yan YQ, Liu YK, Lewandrowski KU: Comparative study of curative effect of spinal endoscopic surgery and anterior cervical decompression for cervical spondylotic myelopathy. J Spine Surg 6(Suppl 1):S186-S196, 2020

32. Ahn Y, Lee SH, Park WM, Lee HY: Posterolateral percutaneous endoscopic lumbar foraminotomy for L5-S1 foraminal or lateral exit zone stenosis. Technical note. J Neurosurg 99(3 Suppl):320323, 2003

33. Kim HS, Ju C Il, Kim SW, Kim JG: Endoscopic transforaminal suprapedicular approach in high grade inferior migrated lumbar disc herniation. J Korean Neurosurg Soc 45(2):67-73, 2009

34. Lim KT, Wi Nam HG, Kim SB, Kim HS, Park JS, Park CK: Therapeutic feasibility of full endoscopic decompression in one- to three-level lumbar canal stenosis via a single skin port using a new endoscopic system, percutaneous stenoscopic lumbar decompression. Asian Spine J 13(2):272-282, 2019

35. Knight MTN, Goswami A, Patko JT, Buxton N: Endoscopic foraminoplasty: A prospective study on 250 consecutive patients with independent evaluation. J Clin Laser Med Surg 19(2):7381,2001

36. Ito F, Ito Z, Shibayama M, Nakamura S, Yamada M, Yoshimatu $\mathrm{H}$, et al.: Step-by-step sublaminar approach with a newly-desig-ned spinal endoscope for unilateral-approach bilateral decompression in spinal stenosis. Neurospine 16(1):41-51, 2019

37. Kambin P SS: Posterolateral percutaneous suction-excision of her niated lumbar intervertebral discs. Report of interim results. Clin Orthop Relat Res 207:37-43, 1986

38. Hijikata S: Percutaneous nucleotomy. A new concept technique and 12 years' experience. Clin Orthop 238:9-23, 1989

39. Birkenmaier C, Komp M, Leu HF, Wegener B, Ruetten S. The current state of endoscopic disc surgery: Review of controlled studies comparing full-endoscopic procedures for disc herniations to standard procedures. Pain Physician 16(4):335-44, 2013

40. Ahn Y, Youn MS, Heo DH: Endoscopic transforaminal lumbar interbody fusion: A comprehensive review. Expert Rev Med Devices [Internet] 16(5):373-380, 2019 Available from: https:/doi. org/10.1080/17434440.2019.1610388

41. Kambin P, O'Brien E, Zhou L, et al.: Arthroscopic microdiscectomy and selective fragmentectomy. Clin Orthop Relat Res 347: 150-167, 1998

42. Pairaiturkar PP, Sudame OS, Pophale CS: Evaluation of Dimensions of Kambin's Triangle to Calculate Maximum Permissible Cannula Diameter for Percutaneous Endoscopic Lumbar Discectomy: A 3-Dimensional Magnetic Resonance Imaging Based Study. J Korean Neurosurg Soc Jul;62(4):414-421, 2019

43. Hofstetter CP, Ahn Y, Choi G, Gibson JNA, Ruetten S, Zhou Y, et al.: AOSpine Consensus Paper on Nomenclature for WorkingChannel Endoscopic Spinal Procedures. Glob Spine J 10(Suppl 2): 111S-121S, 2020

44. Kambin P, Gellman H: Percutaneous lateral discectomy of the lumbar spine a preliminary report. Clin Orthop Relat Res 174: 127-132, 1983

45. Kambin P: Arthroscopic microdiskectomy. J Med 58(2):159-164, 1992

46. Mirkovic SR, Schwartz DG, Glazier KD: Anatomic Considerations in Lumbar Posterolateral Percutaneous Procedures. Spine (Phila Pa 1976) [Internet]. Sep 1 [cited $2021 \mathrm{Feb} ; 20$ ];20(18): 
1965-1971, 1995 Available from: http://journals.lww. com/0000 7632-199509150-00001

47. Mayer HM, Brock M: Percutaneous endoscopic discectomy: Surgical technique and preliminary results compared to microsurgical discectomy. J Neurosurg 78(2):216-225, 1993

48. Hermantin FU, Peters T, Quartararo L KP: A prospective, randomized study comparing the results of open discectomy with those of video-assisted arthroscopic microdiscectomy. J Bone Joint Surg 81(7):958- 965, 1999

49. Hoogland T, Schubert M, Miklitz B, Ramirez A: Transforaminal posterolateral endoscopic discectomy with or without the combination of a low-dose chymopapain: A prospective randomized study in 280 consecutive cases. Spine (Phila Pa 1976) 31(24):890-897, 2006

50. Ruetten S, Komp M, Merk H, Godolias G: Full-endoscopic interlaminar and transforaminal lumbar discectomy versus conventional microsurgical technique: A prospective, randomized, controlled study. Spine (Phila Pa 1976) 33(9):931-939, 2008

51. Nellensteijn J, Ostelo R, Bartels R, Peul W, Van Royen B, Van Tulder M: Transforaminal endoscopic surgery for symptomatic lumbar disc herniations: A systematic review of the literature. Eur Spine J 19(2):181-204, 2010

52. Cong L, Zhu Y, Tu G: A meta-analysis of endoscopic discectomy versus open discectomy for symptomatic lumbar disk herniation. Eur Spine J 25(1):134-143, 2016

53. Li XC, Zhong CF, Deng GB, Liang RW HC: Full-endoscopic procedures versus traditional discectomy surgery for discectomy: A systematic review and meta-analysis of current global clinical trials. Pain Physician 19(3):103-118, 2016

54. Ruan W, Feng F, Liu Z, Xie J, Cai L, Ping A: Comparison of percutaneous endoscopic lumbar discectomy versus open lumbar microdiscectomy for lumbar disc herniation: A meta-analysis. Int J Surg [Internet] 31:86-92, 2016 Available from: http://dx.doi. org/10.1016/j.ijsu.2016.05.061

55. Choi KY, Eun SS, Lee SH, Lee HY: Percutaneous endoscopic thoracic discectomy; Transforaminal approach. Minim Invasive Neurosurg 53(1):25-28, 2010

56. Obenchain TG: Laparoscopic lumbar discectomy: Case report. J Laparoendosc Surg 1(3):145-149, 1991

57. Rosenthal D, Rosenthal R de SA: Removal of a protruded thoracic disc using microsurgical endoscopy. A new technique. Spine (Phila Pa 1976) 19(9):1087-1091, 1994

58. Krishnan A, Kohli R, Degulmadi D, Mayi S, Ranjan R, Dave B: Cauda equina syndrome: A review of 15 patients who underwent percutaneous transforaminal endoscopic lumbar discectomy (PTELD) under local anaesthesia. Malaysian Orthop J 14(2):101-110, 2020

59. Kim DH, Choi G LS: Endoscopic spine procedures. Thieme 2011

60. Gu Y tong, Cui Z, Shao H wei, Ye Y, Gu A qun: Percutaneous transforaminal endoscopic surgery (PTES) for symptomatic lumbar disc herniation: A surgical technique, outcome, and complications in 209 consecutive cases. J Orthop Surg Res 12(1):1-13, 2017

61. Lewandrowski KU, Dowling Á, de Carvalho PST, Calderaro AL, dos Santos TS, de Limae Silva MS, et al.: Indication and Contraindication of Endoscopic Transforaminal Lumbar Decompression. World Neurosurg [Internet] 145:631-642, 2021 Available from: https://doi.org/10.1016/j.wneu.2020.03.076

62. Hoogland T: Transforaminal endoscopic discectomy with foraminoplasty for lumbar disc herniation. Surg Tech Orthop Trau- matol 40(40):55-120, 2003

63. Ahn Y, Oh HK, Kim H, Lee SH, Lee HN: Percutaneous endoscopic lumbar foraminotomy: An advanced surgical technique and clinical outcomes. Neurosurgery 75(2):124-132, 2014

64. Datar GP, Shinde A BK: Technical consideration of transforaminal endoscopic spine surgery for central herniation. Indian J Pain 31(2):86-93, 2017

65. Krishnan A, Kulkarni M, Singh M, Reddy C, Mayi S, Devanand D, et al.: Trans-foraminal endoscopic uniportal decompression in degenerative lumbar spondylolisthesis: A technical and case report. Egypt J Neurosurg 34(1):331-339, 2019

66. Kim HS, Adsul N, Kapoor A, Choi SH, Kim JH, Kim KJ, et al.: A mobile outside-in technique of transforaminal lumbar endoscopy for lumbar disc herniations. J Vis Exp 2018(138):1-7, 2018

67. Khandge AV, Sharma SB, Kim JS: The Evolution of Transforaminal Endoscopic Spine Surgery. World Neurosurg 145:643656, 2021

68. Kim HS, You JD, Ju C Il: Predictive Scoring and Risk Factors of Early Recurrence after Percutaneous Endoscopic Lumbar Discectomy. Biomed Res Int 2019(13):9-12, 2019

69. Mahesha K: Endoscopic transiliac approach to L5-S1 disc and foramen, technique and results. J Orthop Allied Sci [Internet]. [cited 2021 Feb 20];6(1):22, 2018 Available from: http://www. joas.in/text.asp?2018/6/1/22/234476

70. Jang JS, An SH, Lee SH: Transforaminal percutaneous endoscopic discectomy in the treatment of foraminal and extraforaminal lumbar disc herniations. J Spinal Disord Tech 19(5):338-343, 2006

71. Fiorenza V, Ascanio F: Percutaneous Endoscopic Transforaminal Outside-In Outside Technique for Foraminal and Extraforaminal Lumbar Disc Herniations - Operative Technique. World Neurosurg [Internet] 130:244-253, 2019 Available from: https://doi. org/10.1016/j.wneu.2019.07.005

72. Lew SM, Mehalic TF, Fagone KL: Transforaminal percutaneous endoscopic discectomy in the treatment of far-lateral and foraminal lumbar disc herniations. J Neurosurg 94(Suppl 2):216-220, 2001

73. Yeung AT Tsou PM: Posterolateral endoscopic excision for lumbar disc herniation: Surgical technique, outcome, and complications in 307 consecutive cases. Spine (Phila Pa 1976) 27:722-231, 2002

74. Lee S, Kim SK, Lee SH, Kim WJ, Choi WC, Choi G, et al.: Percutaneous endoscopic lumbar discectomy for migrated disc herniation: Classification of disc migration and surgical approaches. Eur Spine J 16(3):431-437, 2007

75. Lee $\mathrm{SH}$. Operative failure of percutaneous endoscopic lumbar discectomy: A radiologic analysis of 55 cases. Spine (Phila Pa 1976). 31(10):285-290, 2006

76. Choi G, Lee S, Lokhande P, Kong BJ: Percutaneous Endoscopic Approach for Highly Migrated Intracanal Disc Herniations by Foraminoplastic Technique Using Rigid Working Channel Endoscope. Spine J 33(15):508-515, 2008

77. Lee CW, Yoon KJ, Ha SS, Kang JK: Foraminoplastic superior vertebral notch approach with reamers in percutaneous endoscopic lumbar discectomy: Technical note and clinical outcome in limited indications of percutaneous endoscopic lumbar discectomy. J Korean Neurosurg Soc 59(2):172-781, 2016

78. Kim HS, Yudoyono F, Paudel B, Kim KJ, Jang JS, Choi JH, et 
al.: Suprapedicular Circumferential Opening Technique of Percutaneous Endoscopic Transforaminal Lumbar Discectomy for High Grade Inferiorly Migrated Lumbar Disc Herniation. Biomed Res Int. 2018:11-15, 2018

79. Uniyal P, Choi G, Khedkkar B: Percutaneous transpedicular lumbar endoscopy: A case report. Int J Spine Surg 1(10):1-7, 2016

80. Qing-Feng Hu, Hao Pan, Yi-You Fang GJ: Percutaneous endoscopic lumbar discectomy for high-grade down-migrated disc using a trans-facet process and pedicle-complex approach: A technical case series. Eur Spine J 27(Suppl 3):393-402, 2018

81. Lee SH, Kang HS, Choi G, Kong BJ, Ahn Y, Kim JS, et al.: Foraminoplastic ventral epidural approach for removal of extruded herniated fragment at the L5-S1 level. Neurol Med Chir (Tokyo) 50(12):1074-1078, 2010

82. Eun SS, Lee SH, Liu WC, Erken HY: A novel preoperative trajectory evaluation method for L5-S1 transforaminal percutaneous endoscopic lumbar discectomy. Spine J [Internet] 18(7):12861291, 2018 Available from: https://doi.org/10.1016/j.spinee. 2018. 02.021

83. Patgaonkar P, Datar G, Agrawal U, Palanikumar C, Agrawal A, Goyal V, et al.: Suprailiac versus transiliac approach in transforaminal endoscopic discectomy at L5-S1: A new surgical classification of L5-iliac crest relationship and guidelines for approach. J Spine Surg 6(Suppl 1):S145-S154, 2020

84. Tezuka F, Sakai T, Abe M, Yamashita K, Takata Y, Higashino $\mathrm{K}$, et al.: Anatomical considerations of the iliac crest on percutaneous endoscopic discectomy using a transforaminal approach. Spine J [Internet] 17(12):1875-1880, 2017 Available from: http:/ dx.doi.org/10.1016/j.spinee.2017.06.012

85. Choi KC, Park CK: Percutaneous endoscopic lumbar discectomy for L5-S1 disc herniation: Consideration of the relation between the iliac crest and L5-S1 disc. Pain Physician [Internet]. Feb; 1 [cited 2021 Feb 7];19(2):E301-8, 2016 Available from: https:// pubmed.ncbi.nlm.nih.gov/26815257/

86. Ren C, Li Y, Qin R, Sun P, Wang P: Transforaminal Endoscopic Lumbar Discectomy for Lumbar Disc Herniation Causing Bilateral Symptoms. World Neurosurg [Internet] 106:413-421, 2017 Available from: http://dx.doi.org/10.1016/j.wneu.2017.06.191

87. Jasper GP, Francisco GM, Telfeian AE: Transforaminal endoscopic discectomy with foraminoplasty for the treatment of spondylolisthesis. Pain Physician 17(6):E703-E708, 2014

88. Li XF, Jin LY, Lv ZD, Su XJ, Wang K, Song XX, et al.: Endoscopic Ventral Decompression for Spinal Stenosis with Degenerative Spondylolisthesis by Partially Removing Posterosuperior Margin Underneath the Slipping Vertebral Body: Technical Note and Outcome Evaluation. World Neurosurg [Internet] 126:e517525, 2019 Available from: https://doi.org/10.1016/j.wneu. 2019. 02.083

89. Namboothiri PE S: Novel Surgical Technique for Discogenic Cauda Equina Syndrome - Transforaminal Intra Discal Access by Annulotomy outside Central Spinal Canal. J Spine 01(S7), 2016

90. Xie P, Feng F, Chen Z, He L, Yang B, Chen R, et al.: Percutaneous transforaminal full endoscopic decompression for the treatment of lumbar spinal stenosis. BMC Musculoskelet Disord 21 (1):1-8, 2020

91. Bhanot A, Raiturker P, Kashyap A, Arora M: Transforaminal endoscopic surgery in lumbar spine: Technical aspects, current status, and evolving scope. Indian Spine J 3(1):54, 2020
92. Bae JS, Lee SH: Transforaminal full-endoscopic lumbar discectomy in obese patients. Int J Spine Surg [Internet] 10:18, 2016 Available from: http://dx.doi.org/10.14444/3018

93. Ahn Y, Lee HY, Lee SH, Lee JH: Dural tears in percutaneous endoscopic lumbar discectomy. Eur Spine J 20(1):58-64, 2011

94. Li J, Yan D, Duan L, Zhang Z, Zhu H, Zhang Z: Percutaneous discectomy and drainage for postoperative intervertebral discitis. Arch Orthop Trauma Surg 131(2):173-178, 2011

95. Choi EJ, Kim SY, Kim HG, Shon HS, Kim TK, Kim KH: Percutaneous endoscopic debridement and drainage with four different approach methods for the treatment of spinal infection. Pain Physician 20(6):E933-E940, 2017

96. Krishnan A, Barot M, Dave B, Bang P, Devanand D, Patel D, et al.: Percutaneous transforaminal endoscopic discectomy and drainage for spondylodiscitis: A technical note and review of literature. J Orthop Allied Sci 6(3):16, 2018

97. Mahesha K: Transforaminal Endoscopic Drainage of Massive Anterior Epidural Abscess-Novel Technique. J Minim Invasive Spine Surg Tech [Internet] Oct; 8 [cited 2021 Feb 16];5(2):7680, 2020 Available from:www.jmisst.org

98. Aprill C BN. High-intensity zone: A diagnostic sign of painful lumbar disc on magnetic resonance imaging. Br J Radiol 65(773): 361-369, 1992

99. Saifuddin A, Braithwaite I, White J, Taylor BA RP: The Value of Lumbar Spine Magnetic Resonance Imaging in the Demonstration of Anular Tears. Spine (Phila Pa 1976) 40(18):453-457, 1998

100. Munter FM, Wasserman BA, Wu HM, Yousem DM: Serial MR imaging of annular tears in lumbar intervertebral disks. Am J Neuroradiol 23(7):1105-1109, 2002

101. Resnick DK, Choudhri TF, Dailey AT, Groff MW, Khoo L, Matz PG, et al.: Guidelines for the performance of fusion procedures for degenerative disease of the lumbar spine. Part 6: magnetic resonance imaging and discography for patient selection for lumbar fusion. J Neurosurg Spine 2(6):662-669, 2005

102. Peng B, Hou S, Wu W, Zhang C, Yang Y: The pathogenesis and clinical significance of a high-intensity zone (HIZ) of lumbar intervertebral disc on MR imaging in the patient with discogenic low back pain. Eur Spine J 15(5):583-587, 2006

103. Dongfeng R, Hou S, Wu W, Wang H, Shang W, Tang J, et al.: The expression of tumor necrosis factor- $\mathrm{a}$ and CD68 in highintensity zone of lumbar intervertebral disc on magnetic resonance image in the patients with low back pain. Spine (Phila Pa 1976) 36(6):429-433, 2011

104. Jha SC, Higashino K, Sakai T, Takata Y, Abe M, Yamashita K, et al.: Clinical significance of high-intensity zone for discogenic low back pain: A review. J Med Investig 63(1-2):1-7, 2016

105. Tsou PM, Yeung CA, Yeung AT: Posterolateral transforaminal selective endoscopic discectomy and thermal annuloplasty for chronic lumbar discogenic pain: A minimal access visualized intradiscal surgical procedure. Spine J 4(5):564-573, 2004

106. Namboothiri S, Gore S, Veerasekhar G: Treatment of low back pain by treating the annular high intensity zone (HIZ) lesions using percutaneous transforaminal endoscopic disc surgery. Int J Spine Surg 12(3):388-392, 2018

107. Kreiner DS, Shaffer WO, Baisden JL, Gilbert TJ, Summers JT, Toton JF, et al.: An evidence-based clinical guideline for the diagnosis and treatment of degenerative lumbar spinal stenosis (update). Spine J [Internet] 13(7):734-743, 2013 Available from: 
http://dx.doi.org/10.1016/j.spinee.2012.11.059

108. Englund J: Lumbar spinal stenosis. Curr Sports Med Rep. 6 (1):50-55, 2007

109. Inose H, Yamada T, Hirai T, Yoshii T, Abe Y, Okawa A: The impact of sarcopenia on the results of lumbar spinal surgery. Osteoporos Sarcopenia [Internet] 4(1):33-36, 2018 Available from: https://doi.org/10.1016/j.afos.2018.02.003

110. Li ZZ, Hou SX, Shang WL, Cao Z, Zhao HL: Percutaneous lumbar foraminoplasty and percutaneous endoscopic lumbar decompression for lateral recess stenosis through transforaminal approach: Technique notes and 2 years follow-up. Clin Neurol Neurosurg [Internet] 143:90-94, 2016 Available from: http://dx.doi.org/10.1016/j.clineuro.2016.02.008

111. Cheng XK, Cheng Y pei, Liu ZY, Bian FC, Yang FK, Yang N, et al.: Percutaneous transforaminal endoscopic decompression for lumbar spinal stenosis with degenerative spondylolisthesis in the elderly. Cin Neurol Neurosurg [Internet] 194(March), 2020 105918. Available from: https://doi.org/10.1016/j. clineuro.2020. 105918

112. Lee $\mathrm{CH}$, Choi M, Ryu DS, Choi I, Kim CH, Kim HS, et al.: Efficacy and safety of full-endoscopic decompression via interlaminar approach for central or lateral recess spinal stenosis of the lumbar spine: A meta-analysis. Spine (Phila Pa 1976) 43 (24):1756-1764, 2018

113. Hsu HT, Chang SJ, Yang SS, Chai CL: Learning curve of fullendoscopic lumbar discectomy. Eur Spine J 22(4):727-733, 2013

114. Moon ASM, Manoharan SRR: Endoscopic spine surgery: Current state of art and the future perspective. Asian Spine J 12(1): 1-2, 2018

115. Choi KC, Lee JH, Kim JS, Sabal LA, Lee S, Kim H, et al.: Unsuccessful percutaneous endoscopic lumbar discectomy: A singlecenter experience of 10228 cases. Neurosurgery 76(4):372-380, 2015

116. Peng CWB, Yeo W, Tan SB. Percutaneous endoscopic lumbar discectomy: Clinical and quality of life outcomes with a minimum 2 year follow-up. J Orthop Surg Res 4:20, 2009

117. Wang H, Zhou Y, Li C, Liu J, Xiang L: Risk factors for failure of single-level percutaneous endoscopic lumbar discectomy. J Neurosurg Spine 23(3):320-325, 2015

118. Komp M, Hahn P, Ozdemir S, Merk H, Kasch R, Godolias $\mathrm{G}$, et al.: Operation of lumbar zygoapophyseal joint cysts using a full-endoscopic interlaminar and transforaminal approach: Prospective 2-year results of 74 patients. Surg Innov Dec 21(6): 605-614, 2014

119. Yeung A, Gore S: Endoscopic foraminal decompression for failed back surgery syndrome under local anesthesia. Int J Spine Surg [Internet] 8:22, 2014 Available from: http://dx.doi.org/10.14444/ 1022

120. Simmonds AM, Rampersaud YR, Dvorak MF, Dea N, Melnyk $\mathrm{AD}$, Fisher CG: Defining the inherent stability of degenerative spondylolisthesis: A systematic review. J Neurosurg Spine 23 (2):178-189, 2015

121. Telfeian AE, Oyelese A, Fridley J, Gokaslan ZL: Transforaminal Endoscopic Decompression in the Setting of Lateral Lumbar Spondylolisthesis. World Neurosurg [Internet] 117:321-325, 2018 Available from: https://doi.org/10.1016/j.wneu.2018.06.106

122. Osman SG: Endoscopic transforaminal decompression, interbody fusion, and percutaneous pedicle screw implantation of the lumbar spine: A case series report. Int J Spine Surg [Internet] 6(1):157-166, 2012 Available from: http://dx.doi.org/10.1016/ j.ijsp.2012.04.001

123. Wang MY, Grossman J: Endoscopic minimally invasive transforaminal interbody fusion without general anesthesia: Initial clinical experience with 1-year follow-up. Neurosurg Focus 40(2): $1-5,2016$

124. Morgenstern R: Full Endoscopic Transforaminal Lumbar Interbody Fusion Approach with Percutaneous Posterior Transpedicular Screw Fixation in a Case of Spondylolisthesis Grade I with L4-5 Central Stenosis. J Crit Spine Cases 3(1):115-119, 2010

125. Morgenstern R, Morgenstern C: Percutaneous transforaminal lumbar interbody fusion (pTLIF) with a posterolateral approach for the treatment of degenerative disk disease: Feasibility and preliminary results. Int J Spine Surg [Internet] 9:41, 2015 Available from: http://dx.doi.org/10.14444/2041

126. Jacquot F, Gastambide D: Percutaneous endoscopic transforaminal lumbar interbody fusion: Is it worth it? Int Orthop 37 (8):1507-1510, 2013

127. Syed H, Voyadzis JM: True Percutaneous Transforaminal Lumbar Interbody Fusion: Case Illustrations, Surgical Technique, and Limitations. J Neurol Surgery, A Cent Eur Neurosurg 77(4):344 353, 2015

128. Lee SH, Erken HY, Bae J: Percutaneous Transforaminal Endoscopic Lumbar Interbody Fusion: Clinical and Radiological Results of Mean 46-Month Follow-Up. Biomed Res Int 2017;2017

129. Choi KC, Lee DC PC: Percutaneous Endoscopic Lumbar Foraminoplasty for Resection of Synovial Cyst. J Minim Invasive Spine Surg \& Tech 1(1):36-39, 2016

130. Ahn Y: Transforaminal percutaneous endoscopic lumbar discectomy: Technical tips to prevent complications. Expert Rev Med Devices 9(4):361-366, 2012

131. Zhou C, Zhang G, Panchal RR, Ren X, Xiang H, Xuexiao $\mathrm{M}$, et al.: Unique complications of percutaneous endoscopic lumbar discectomy and percutaneous endoscopic interlaminar discectomy. Pain Physician 21(2):E105-E112, 2018

132. Ahn Y, Lee S-H: Laser-assisted Transforaminal Endoscopic Lumbar Discectomy: Technical Pearls for Prevention of Complications. Med Lasers 2(2):43-48, 2013

133. Kapetanakis S, Gkasdaris G, Angoules AG, Givissis P: Transforaminal percutaneous endoscopic discectomy using transforaminal endoscopic Spine system technique: Pitfalls that a beginner should avoid. World J Orthop 8(12):874-880, 2017

134. Goald HJ: Microlumbar discectomy: Followup of 147 patients. Spine (Phila Pa 1976) 3(2):183-185, 1978

135. Wilson DH KJ: Microsurgical lumbar discectomy: Preliminary report of 83 consecutive cases. Neurosurgery 4(2):137-140, 1979

136. Ruetten S, Komp M, Merk H, Godolias G: Full-endoscopic interlaminar and transforaminal lumbar discectomy versus conventional microsurgical technique: A prospective, randomized, controlled study. Spine (Phila Pa 1976) 33(9):931-939, 2008

137. Tonosu J, Oshima Y, Shiboi R, Hayashi A, Takano Y, Inanami $\mathrm{H}$, et al.: Consideration of proper operative route for interlaminar approach for percutaneous endoscopic lumbar discectomy. J Spine Surg 2(4):281-288, 2016

138. Ruetten S, Komp M, Godolias G: A new full-endoscopic technique for the interlaminar operation of lumbar disc herniations using 6-mm endoscopes: Prospective 2-year results of 331 patients. Minim 
Invasive Neurosurg 49(2):80-87, 2006

139. Eun SS, Chachan S, Lee SH: Interlaminar Percutaneous Endoscopic Lumbar Discectomy: Rotate and Retract Technique. World Neurosurg 118:188-192, 2018 Available from: https://doi.org/ 10.1016/j.wneu.2018.07.083

140. Kim $\mathrm{CH}$, Chung CK: Endoscopic interlaminar lumbar discectomy with splitting of the ligament flavum under visual control. J Spinal Disord Tech 25(4):210-217, 2012

141. Lee J, Kim H, Jang J, Jang I: Interlaminar Discectomy for L5-S1 Herniated Nucleus Pulposus 2016;2016

142. Ruetten S, Komp M, Merk H, Godolias G: Surgical treatment for lumbar lateral recess stenosis with the full-endoscopic interlaminar approach versus conventional microsurgical technique: A prospective, randomized, controlled study. J Neurosurg Spine 10(5):476-485, 2009

143. McGirt MJ, Garcé Ambrossi GL, Datoo G, Sciubba DM, Witham TF, Wolinsky JP, et al.: Recurrent disc herniation and longterm back pain after primary lumbar discectomy: Review of outcomes reported for limited versus aggressive disc removal. Neurosurgery 64(2):338-344, 2009

144. Chen KT, Tseng C, Sun LW, Chang KS, Chen CM: Technical Considerations of Interlaminar Approach for Lumbar Disc Herniation. World Neurosurg Jan;145:612-620, 2021

145. Chao Shi, Weijun Kong, Wenbo Liao, Yanxiao Lu, Yao Fu, Hongquan Wen, Qian Du, Fujun Wu: "The Early Clinical Outcomes of a Percutaneous Full-Endoscopic Interlaminar Approach via a Surrounding Nerve Root Discectomy Operative Route for the Treatment of Ventral-Type Lumbar Disc Herniation", BioMed Research International, Vol. 2018, Article ID 9157089 , 6 pages, 2018

146. Nam HGW, Kim HS, Lee DK, Park CK, Lim KT: Percutaneous stenoscopic lumbar decompression with paramedian approach for foraminal/extraforaminal lesions. Asian Spine J 13(4):672681, 2019

147. Hurley ET, Maye AB, Timlin M, Lyons FG: Anterior Versus Posterior Thoracic Discectomy. A Systematic Review Spine (Phila Pa 1976) 42(24):E1437-E145, 2017

148. Moon SJ, Lee JK, Jang JW, Hur H, Lee JH, Kim SH: The trans dural approach for thoracic disc herniations: A technical note. Eur Spine J 19(7):1206-1211, 2010

149. Le Roux, Peter D, Haglund, Michael M, Harris, A. Basil: Thoracic Disc Disease: Experience with the Transpedicular Approach in Twenty Consecutive Patients Technique and Application. Neurosurgery 33:58-66, 1993

150 Schmidt MH, Larson SJ, Maiman DJ: The lateral extracavitary approach to the thoracic and lumbar spine. Neurosurg Clin $\mathrm{N}$ Am 15(4):437-441, 2004

151. Krishnan A, Degulmadi D, Mayi S, Kulkarni M, Reddy C, Singh M, et al.: Transforaminal Thoracic Interbody Fusion for Thoracic Disc Prolapse: Surgicoradiological Analysis of 18 Cases. Glob Spine J 10(6):706-714, 2020

152. Robinson WA, Nassr AN, Sebastian AS: Thoracic disc herniation, avoidance, and management of the surgical complications. Int Orthop 43(4):817-823, 2019

153. Lubelski D, Abdullah KG, Steinmetz MP, Masters F, Benzel EC, Mroz TE, et al.: Lateral extracavitary, costotransversectomy, and transthoracic thoracotomy approaches to the thoracic spine: Review of techniques and complications. J Spinal
Disord Tech 26(4):222-232, 2013

154. Regev GJ, Salame K, Behrbalk E, Keynan O, Lidar Z: Minimally invasive transforaminal, thoracic microscopic discectomy: Technical report and preliminary results and complications. Spine J [Internet] 12(7):570-576, 2012 Available from: http://dx.doi. org/10.1016/j.spinee.2012.07.001

155. Hanna G, Kim TT, Uddin SA, Ross L, Johnson JP: Video-assisted thoracoscopic image-guided spine surgery: Evolution of 19 years of experience, from endoscopy to fully integrated 3D navigation. Neurosurg Focus 50(1):1-7, 2021

156. Hur JW, Kim JS, Cho DY, Shin JM, Lee JH, Lee SH: VideoAssisted Thoracoscopic Surgery under O-Arm Navigation System Guidance for the Treatment of Thoracic Disk Herniations: Surgical Techniques and Early Clinical Results. J Neurol Surgery, A Cent Eur Neurosurg 75(6):415- 421, 2014

157. Sharma SB, Kim JS: A review of minimally invasive surgical techniques for the management of thoracic disc herniations. Neurospine 16(1):24-33, 2019

158. Bae J, Chachan S, Shin SH, Lee SH: Transforaminal endoscopic thoracic discectomy with foraminoplasty for the treatment of thoracic disc herniation. J Spine Surg 6(2):397-404, 2020

159. Choi G, Munoz-Suarez D: Transforaminal endoscopic thoracic discectomy: Technical review to prevent complications. Neurospine 17(Suppl 1):S58-65, 2020

160. Gibson RDS, Wagner R, Gibson JNA: Full endoscopic surgery for thoracic pathology: An assessment of supportive evidence. EFORT Open Rev 6(1):50-60, 2021

161. Ruetten S, Hahn P, Oezdemir S, Baraliakos X, Merk H, Godolias $\mathrm{G}$, et al.: Full-endoscopic uniportal decompression in disc herniations and stenosis of the thoracic spine using the interlaminar, extraforaminal, or transthoracic retropleural approach. J Neurosurg Spine 29(2):157-168, 2018

162. Li X, An B, Gao H, Zhou C, Zhao X, Ma H, et al.: Surgical results and prognostic factors following percutaneous full endoscopic posterior decompression for thoracic myelopathy caused by ossification of the ligamentum flavum. Sci Rep 10(1):1-9, 2020

163. Xin Z, Kong W, Cai M, Du Q, Liu L, He J, Qin J, Wang A, Ao J LW: Translaminar Osseous Channel-Assisted Full-Endoscopic Flavectomy Decompression of Thoracic Myelopathy Caused by Ossification of the Ligamentum Flavum: Surgical Technique and Results. Pain Physician 23(5):475-486, 2020

164. Bae J, Chachan S, Shin SH, Lee SH: Percutaneous endoscopic thoracic discectomy in the upper and midthoracic Spine: A technical note. Neurospine 16(1):148-153, 2019

165. Ahn Y, Keum HJ, Shin SH: Percutaneous Endoscopic Cervical Discectomy versus Anterior Cervical Discectomy and Fusion: A Comparative Cohort Study with a Five-Year Follow-Up. J Clin Med 9(2):371, 2020

166. Ahn Y: Percutaneous endoscopic cervical discectomy using working channel endoscopes. Expert Rev Med Devices 13(6):601610, 2016

167. Ren Y, Yang J, Chen CM, Chen CM, Chen CM, Liu K, et al.: Outcomes of Discectomy by Using Full-Endoscopic Visualization Technique via the Transcorporeal and Transdiscal Approaches in the Treatment of Cervical Intervertebral Disc Herniation: A Comparative Study. Biomed Res Int 2020:5613459, 2020

168. Ruetten S: Full-endoscopic anterior decompression versus con- 
ventional anterior decompression and fusion in cervical disc herniations. Int Orthop Dec;33(6):1677-1682, 2009

169. Oertel JMK, Philipps M, Burkhardt BW: Endoscopic Posterior Cervical Foraminotomy as a Treatment for Osseous Foraminal Stenosis. World Neurosurg [Internet] 91:50-57, 2016 Available from: http://dx.doi.org/10.1016/j.wneu.2016.02.073

170. Yu KX, Lu WZ, Xiao CM, Chu L, Deng R, Chen L, et al.: Posterior percutaneous transpedicular endoscopic approach for treating single-segment cervical myelopathy. Biomed Res Int 2020:1573589, 2020

171. Ahn Y: The Current State of Cervical Endoscopic Spine Surgery: An Updated Literature Review and Technical Considerations. Expert Rev Med Devices [Internet] 17(12):1285-1292, 2020 Available from: https://doi.org/10.1080/17434440. 2020. 1853523

172. Yu KX, Chu L, Yang JS, Deng R, Chen L, Shi L, et al.: Anterior Transcorporeal Approach to Percutaneous Endoscopic Cervical Diskectomy for Single-Level Cervical Intervertebral Disk Herniation: Case Series with 2-Year Follow-Up. World Neurosurg Feb 1;122:e1345-1353, 2019

173. Kong W, Xin Z, Du Q, Cao G, Liao W: Anterior percutaneous full-endoscopic transcorporeal decompression of the spinal cord for single-segment cervical spondylotic myelopathy: The technical interpretation and 2 years of clinical follow-up. J Orthop Surg Res 14(1):1-8, 2019

174. Zdeblick TA, Zou D, Warden KE, McCabe R, Kunz D, Vanderby R: Cervical stability after foraminotomy. A biomechanical in vitro analysis. J Bone Jt Surg - Ser A [nternet] Jan 1 [cited 2021 Feb 16];4(1):22-27, 1992 Available from: https:// europepmc.org/article/med/1734010

175. Lin Y, Rao S, Li Y, Zhao S, Chen B: Posterior Percutaneous FullEndoscopic Cervical Laminectomy and Decompression for Cervical Stenosis with Myelopathy: A Technical Note. World Neurosurg S1878-8750(19):30051, 2019 Available from: https://doi.org/ 10.1016/j.wneu.2018.12.180

176. Carr DA, Abecassis IJ, Hofstetter CP: Full endoscopic unilateral laminotomy for bilateral decompression of the cervical spine: Surgical technique and early experience. J Spine Surg 6(2):447-456, 2020

177. Bucknall V, Gibson JNA: Cervical endoscopic spinal surgery: A review of the current literature. J Orthop Surg 26(1):1-8, 2018

178. Hellinger S: The fullendoscopic anterior cervical fusion: A new horizon for selective percutaneous endoscopic cervical decompression. Acta Neurochir 108(Suppl):203-207, 2011

179. Yuan H, Zhang X, Zhang LM, Yan YQ Liu YK, Lewandrowski $\mathrm{KU}$ : Comparative study of curative effect of spinal endoscopic surgery and anterior cervical decompression for cervical spondylotic myelopathy. J Spine Surg 6(Suppl 1):S186-196, 2020

180. Ruetten S, Hahn P, Oezdemir S, Baraliakos X, Merk H, Godolias $\mathrm{G}$, et al.: The full-endoscopic uniportal technique for decompression of the anterior craniocervical junction using the retropharyngeal approach: An anatomical feasibility study in human cadavers and review of the literature. J Neurosurg Spine 29(6): 615-621, 2018

181. Ruetten S, Hahn P, Oezdemir S, Baraliakos X, Merk H, Godolias $\mathrm{G}$, et al.: Full-endoscopic uniportal odontoidectomy and decompression of the anterior cervicomedullary junction using the retropharyngeal approach. Spine (Phila Pa 1976) 43(15):
E911-18, 2018

182. Ruetten S, Hahn P, Oezdemir S, Baraliakos X, Godolias G, Komp M: Full-endoscopic uniportal retropharyngeal odontoidectomy for anterior craniocervical infection. Minim Invasive Ther Allied Technol [Internet] 28(3):178-185, 2019 Available from: https://doi.org/10.1080/13645706.2018.1498357

183. Moon BJ, Yi S, Ha Y, Kim KN, Yoon DH, Shin DA: Clinical efficacy and safety of trans-sacral epiduroscopic laser decompression compared to percutaneous epidural neuroplasty. Pain Res Manag 2019:2893460, 2019

184. Jo DH, Yang HJ: The survey of the patient received the epiduroscopic laser neural decompression. Korean J Pain 26(1):27-31, 2013

185. Jo DH, Yang HJ, Kim JJ: Approach for epiduroscopic laser neural decompression in case of the sacral canal stenosis. Korean J Pain 26(4):392-395, 2013

186. Jo DH, Kim ED, Oh HJ: The comparison of the result of epiduroscopic laser neural decompression between FBSS or not. Korean J Pain 27(1):63-67, 2014

187. Schutze G: Epiduroscopy: Spinal endoscopy. Springer Berlin Heidelb pp2-7, 2009

188. Lee SH, Lee SH, Lim KT: Trans-Sacral Epiduroscopic Laser Decompression for Symptomatic Lumbar Disc Herniation: A Preliminary Case Series. Photomed Laser Surg 34(3):121-129, 2016

189. Son S, Yoo CJ, Yoo BR, Kim WS, Jeong TS: Learning curve of trans-sacral epiduroscopic laser decompression in herniated lumbar disc disease. BMC Surg [Internet] 21(1):1-10, 2021 Available from: https://doi.org/10.1186/s12893-020-00949-8

190. Son S, Lee SG, Ahn Y, Kim WK, Jeong TS. Outcomes of epiduroscopic laser ablation in patients with lumbar disc herniation. Medicine (Baltimore) 99(51):e23337, 2020

191. Ito Z, Shibayama M, Nakamura S, Yamada M, Kawai M, Shimizu K, et al.: Postoperative outcomes after transsacral epiduroscopic laser decompression in japanese patients: Denervation therapy for discogenic low-back pain. Photobiomodulation, Photomedicine, Laser Surg 38(8):507-511, 2020

192. Jung YJ, Chang MC: Bacterial meningitis and cauda equina syndrome after trans-sacral epiduroscopic laser decompression: A case report. Med (United States) 98(11):4-6, 2019

193 Richter EO RL: Minimally invasive anterior epidural endoscopic disc and neural decompression. J Neurosurg Rev Suppl 1: 20-28, 2011

194. Ülgen AM, Beyaz SG, Inanmaz ME, Şahin F: Evaluation of the Efficacy of Epiduroscopic Laser Neural Discectomy in Lumbar Disc Herniations: Retrospective Analysis of 163 Cases-Evaluation of the Efficacy of ELNP. Pain Res Manag 2020(July 2016), 2020

195. Chang MC: Sacral root injury during trans-sacral epiduroscopic laser decompression. Med (United States) 96(42):6-8, 2017

196. Tonami H, Kuginuki M, Kuginuki Y, Matoba M, Yokota H, Higashi K, Yamamoto I NY: MR imaging of subchondral osteonecrosis of the vertebral body after percutaneous laser diskectomy. Am J roentgeenology 173(5):1383-1386, 1999

197. Ohnmeiss DD, Guyer RD HS: Laser disc decompression. The importance of proper patient selection. Spine (Phila Pa 1976). 19(18):2054-2058, 1994

198. Kim SK, Lee SC, Park SW, Kim ES: Complications of lumbar 
disc herniations following trans-sacral epiduroscopic lumbar decompression: A single-center, retrospective study. J Orthop Surg Res 12(1):1-9, 2017

199. Erbas YC, Pusat S, Erdogan E: Percutaneous laser disc decompression: Retrospective analysis of 197 cases and review of the literature. Turk Neurosurg 25(5):766-770, 2015

200. Yu Y, Kim TH, Lee SH, Chang MC: Epidural Hematoma after Trans-Sacral Epiduroscopic Laser Decompression: A Case Report. Photobiomodulation, Photomedicine, Laser Surg 38(2):112114, 2020

201. Bosacco SJ, Gardner MJ, Guille JT: Evaluation and Treatment of Dural Tears in lumbar spine surgery: A review. Clin Orthop Relat Res 389:238-247, 2001

202. Kim HS, Ju C Il, Kim SW, Kim JG: Huge psoas muscle hematoma due to lumbar segmental vessel injury following percutaneous endoscopic lumbar discectomy. J Korean Neurosurg Soc 45(3):192-195, 2009

203. Ahn Y, Jin UK, Byung HL, Lee SH, Jong DP, Dong HH, et al.: Postoperative retroperitoneal hematoma following transforaminal percutaneous endoscopic lumbar discectomy: Clinical article. J Neurosurg Spine 10(6):595-602, 2009

204. Cho JY, Lee SH, Lee HY: Prevention of development of postoperative dysesthesia in transforaminal percutaneous endoscopic lumbar discectomy for intracanalicular lumbar disc herniation: Floating retraction technique. Minim Invasive Neurosurg 54(5-6):214-218, 2011

205. Ahn Y, Lee SH: Postoperative spondylodiscitis following transforaminal percutaneous endoscopic lumbar discectomy: Clini$\mathrm{cal}$ characteristics and preventive strategies. $\mathrm{Br} \mathrm{J}$ Neurosurg 26(4):482-486, 2012

206. Choi I, Ahn JO, So WS, Lee SJ, Choi IJ, Kim H. Exiting root injury in transforaminal endoscopic discectomy: Preoperative image considerations for safety. Eur Spine J 22(11):2481-2487, 2013

207. Morgenstern R, Morgenstern C, Yeung AT: The Learning Gurve in Foraminal Endoscopic Discectomy: Experience Needed to Achieve a 90\% Success Rate. SAS J [nternet] 1(3):100-107, 2007 Available from: http://dx.doi.org/10.1016/S1935-9810(07) 70054-3

208. Lee DY, Lee SH: Learning curve for percutaneous endoscopic lumbar discectomy. Neurol Med Chir (Tokyo) 48(9):383-388, 2008

209. Fan G, Gu X, Liu Y, Wu X, Zhang H, Gu G, et al.: Lower learning difficulty and fluoroscopy reduction of transforaminal percutaneous endoscopic lumbar discectomy with an accurate preoperative location method. Pain Physician 19(8):E1123-1134, 2016

210. Cheng J, Wang H, Zheng W, Li C, Wang J, Zhang Z, et al.: Reoperation after lumbar disc surgery in two hundred and seven patients. Int Orthop 37(8):1511-1517, 2013

211. Gillard DM, Corenman DS, Dornan GJ: Failed less invasive lumbar spine surgery as a predictor of subsequent fusion outcomes. Int Orthop 38(4):811-815, 2014

212. Lohre R, Wang JC, Lewandrowski KU, Goel DP: Virtual reality in spinal endoscopy: A paradigm shift in education to support spine surgeons. J Spine Surg 6(Suppl 1):S208-S023, 2020

213. Wang Y, Deng M, Wu H, Wu Y, Guo C, Zhang D, et al.: Short-term effectiveness of precise safety decompression via double percutaneous lumbar foraminoplasty and percutaneous endoscopic lumbar decompression for lateral lumbar spinal canal stenosis: A prospective cohort study. BMC Musculoskelet Disord 22(1):1-10, 2021

214. Osman SG NM: Anatomic Treatment-based Classification of Diseased Lumbar Spinal Motion-segment. Int J Neuro Spinal Sci [Internet]. [cited 2021 Feb 18];1(1), 2013 Available from: https://www.skyspineendoscopyinstitute.com/wp-content/uplo ads/2017/10/Anatomic-Treatment-based-classification-of-disea sed-Lumbar-Spinal-Motion-Segment-IJNSS-1-1-1-3.pdf

215. Rasouli MR, Rahimi-Movaghar V, Shokraneh F, Moradi-Lakeh M, Chou R: Minimally invasive discectomy versus microdiscectomy/open discectomy for symptomatic lumbar disc herniation. Cochrane Database Syst Rev 2014(9):CD010328

216. Kamper SJ, Ostelo RWJG, Rubinstein SM, Nellensteijn JM, Peul WC, Arts MP, et al.: Minimally invasive surgery for lumbar disc herniation: A systematic review and meta-analysis. Eur Spine J 23(5):1021-1043, 2014

217. Chen Z, Zhang L, Dong J, Xie P, Liu B, Wang Q, et al.: Percutaneous transforaminal endoscopic discectomy compared with microendoscopic discectomy for lumbar disc herniation: 1-year results of an ongoing randomized controlled trial. J Neurosurg Spine 28(3):300-310, 2018

218. Gibson JNA, Subramanian AS, Scott CEH: A randomised controlled trial of transforaminal endoscopic discectomy vs microdiscectomy. Eur Spine J 26(3):847-856, 2017

219. Gadjradj PS, van Tulder MW, Dirven CMF, Peul WC, Harhangi BS: Clinical outcomes after percutaneous transforaminal endoscopic discectomy for lumbar disc herniation: A prospective case series. Neurosurg Focus 40(2):1-7, 2016

220. Barber SM, Nakhla J, Konakondla S, Fridley JS, Oyelese AA, Gokaslan ZL TA: Outcomes of endoscopic discectomy compared with open microdiscectomy and tubular microdiscectomy for lumbar disc herniations: A meta-analysis. J Neurosurg Spine 31(6):802-815, 2019

221. Iprenburg M: Transforaminal endoscopic surgery in lumbar disc herniation in an economic crisis-the TESSYS method. US Musculoskelet Rev [Internet] [cited 2021 Feb 9];3:47-49, 2008 Available from: http://ci.nii.ac.jp/naid/10030902958/en/

222. Yeom KS, Choi YS: Full endoscopic contralateral transforaminal discectomy for distally migrated lumbar disc herniation. J Orthop Sci 16(3):263-269, 2011

223. Jasper GP, Francisco GM, Telfeian AE: Clinical success of transforaminal endoscopic discectomy with foraminotomy: A retrospective evaluation. Cin Neurol Neurosurg 115(10):19611965, 2013 Available from: http://dx.doi.org/10.1016/ j.clineuro. 2013.05.033

224. Sanusi T, Davis J, Nicassio N, Malik I: Endoscopic lumbar discectomy under local anesthesia may be an alternative to microdiscectomy: A single centre's experience using the far lateral approach. Clin Neurol Neurosurg [Internet] 139:324-327, 2015 Available from: http://dx.doi.org/10.1016/j.clineuro.2015.11.001

225. Ahn SS, Kim SH, Kim DW, Lee BH: Comparison of Outcomes of Percutaneous Endoscopic Lumbar Discectomy and Open Lumbar Microdiscectomy for Young Adults: A Retrospective Matched Cohort Study. World Neurosurg [Internet] 86:250-258, 2016 Available from: http://dx.doi.org/10.1016/j.wneu.2015.09.047 226. Seiger A, Gadjradj PS, Harhangi BS, Van Susante JLC, Peul WC, 
Van Tulder MW, et al.: PTED study: Design of a non-inferiority, randomised controlled trial to compare the effectiveness and cost-effectiveness of percutaneous transforaminal endoscopic discectomy (PTED) versus open microdiscectomy for patients with a symptomatic lumbar disc herniation. BMJ Open 7(12):1-9, 2017

227. Chen KT, Jabri H, Lokanath YK, Song MS, Kim JS: The evolution of interlaminar endoscopic spine surgery. J Spine Surg 6(2): 502-512, 2020

228. Pang Hung Wu, Hyeun-Sung Kim, Il-Tae Jang: A Narrative Review of Development of Full-Endoscopic Lumbar Spine Surgery. Neurospine 17(Suppl 1):S20-S33, 2020

229. Xie TH, Zeng JC, Li ZH, Wang L, Nie HF, Jiang HS, Song YM KQ: Complications of Lumbar Disc Herniation Following Full-endoscopic Interlaminar Lumbar Discectomy: A Large, SingleCenter, Retrospective Study. Pain Physician 20(3):379-387, 2017

230. Chen J, Jing X, Li C, Jiang Y, Cheng S, Ma J: Percutaneous Endoscopic Lumbar Discectomy for L5S1 Lumbar Disc Herniation Using a Transforaminal Approach Versus an Interlaminar Approach: A Systematic Review and Meta-Analysis. World Neurosurg [Internet]. 116:412-420.e2, 2018 Available from: https:// doi.org/10.1016/j.wneu.2018.05.075

231. Kim CH, Chung CK, Woo JW: Surgical Outcome of Percutaneous Endoscopic Interlaminar Lumbar Discectomy for Highly Migrated Disk Herniation. Clin Spine Surg 29(5):E259-266, 2016

232. Yin S, Du H, Yang W, Duan C, Feng C, Tao H: Prevalence of recurrent herniation following percutaneous endoscopic lumbar discectomy: A meta-analysis. Pain Physician 21(4):337-350, 2018

233. Yin J, Jiang Y, Nong L: Transforaminal approach versus interlaminar approach: A meta-analysis of operative complication of percutaneous endoscopic lumbar discectomy. Medicine (Baltimore). Jun;19;99(25):e20709, 2020

234. Epstein N: More nerve root injuries occur with minimally invasive lumbar surgery, especially extreme lateral interbody fusion: A review. Surg Neurol Int 7:S83-S95, 2016

235. Kim HS, Park JY: Comparative assessment of different percutaneous endoscopic interlaminar lumbar discectomy (PEID) techniques. Pain Physician 16(4):359-367, 2013

236. Guan Y, Huang T, An G, Wan R, Wei T, Shi X, et al.: Percutaneous endoscopic interlaminar lumbar discectomy with local anesthesia for L5-S1 disc herniation: A feasibility study. Pain Physician 22(6):E649-654, 2019

237. Qian JI, Yu SS, Liu JJ, Chen L, Jing JH: Biomechanics changes of lumbar spine caused by foraminotomy via percutaneous trans foraminal endoscopic lumbar discectomy. Zhonghua yi xue za zhi 98(13):1013-1018, 2018

238. Ruetten S: The Full-endoscopic Interlaminar Approach for Lumbar Disc Herniations. Minimal Invasive Spine Surg pp346-55, 2006

239. Siepe CJ, Sauer D: Technique of full-endoscopic lumbar discectomy via an interlaminar approach. Eur Spine J [Internet]. 27(March):566-567, 2018 Available from: https://doi.org/10. 1007/s00586-018-5657-2

240. Wang B, Lü G, Patel AA, Ren P, Cheng I: An evaluation of the learning curve for a complex surgical technique: The full endos- copic interlaminar approach for lumbar disc herniations. Spine J 11(2):122-130, 2011

241. Lee SH: Posterolateral Endoscopic Thoracic Discectomy: Transforaminal Approach. Neurol Spinale Med Chir 1(2):20-20, 2018

242. Li ZZ, Zhao HL, Cao Z, Shang WL, Hou SX: [Technical notes and clinical efficacy analysis of full-endoscopic thoracic discectomy via transforaminal approach]. Zhonghua Yi Xue Za Zhi Feb 4;100(4):279-285, 2020

243. Li W, Gao S, Zhang L, Cao C, Wei J: Full-endoscopic decompression for thoracic ossification of ligamentum flavum: surgical techniques and clinical outcomes: A retrospective clinical study. Medicine (Baltimore) 99(44):e22997, 2020

244. Yu Q, Yang J, Chu L, Shi L, Deng Z, Ke Z: Clinical effectiveness of percutaneous endoscopic spinal surgery via transforaminal approach for single-level thoracic ossification of the posterior longitudinal ligament pp1-9, 2020

245. Guo C, Zhu D, Kong Q, Zhang L, Wang Y, Yang J, et al.: Transforaminal Percutaneous Endoscopic Decompression for Lower Thoracic Spinal Stenosis. World Neurosurg [nternet]. 1(128):504-512, 2019 Available from: https://doi.org/10.1016/ j.wneu.2019.04.186

246. Nie HF, Liu KX: Endoscopic transforaminal thoracic foraminotomy and discectomy for the treatment of thoracic disc herniation. Minim Invasive Surg 2013:264105, 2013

247. Wagner R, Telfeian AE, Iprenburg M, Krzok G, Gokaslan Z, Choi DB, et al.: Transforaminal Endoscopic Foraminoplasty and Discectomy for the Treatment of a Thoracic Disc Herniation. World Neurosurg [Internet] 90:194-198, 2016 Available from: http://dx.doi.org/10.1016/j.wneu.2016.02.086

248. O’Toole JE, Sheikh H, Eichholz KM, Fessler RG, Perez-Cruet MJ: Endoscopic Posterior Cervical Foraminotomy and Discectomy. Neurosurg Clin N Am 17(4):411-422, 2006

249. Grieve JP, Kitchen ND, Moore AJ, Marsh HT: Results of posterior cervical foraminotomy for treatment of cervical spondylitic radiculopathy. Br J Neurosurg 14(1):40-43, 2000

250. Zhang M, Yan L, Li S, Li Y, Huang P: Ultrasound-guided transforaminal percutaneous endoscopic lumbar discectomy: A new guidance method that reduces radiation doses. Eur Spine J [Internet] 28(11):2543-2550, 2019 Available from: https://doi. org/10.1007/s00586-019-05980-9

251. Yu L, Wen JK, Wang S, Wang WH, Yu JM, Ye XJ: Removal of calcified lumbar disc herniation with endoscopic-matched ultrasonic osteotome-Our preliminary experience. $\mathrm{Br} \mathrm{J}$ Neurosurg [Internet] 34(1):80-85, 2020 Available from: https://doi. org/10.1080/02688697.2019.1687850

252. Dave BR, Krishnan A, Rai RR, Degulmadi D, Mayi S, Gudhe M: The Effectiveness and Safety of Ultrasonic Bone Scalpel Versus Conventional Method in Cervical Laminectomy: A Retrospective Study of 311 Patients. Glob Spine J 10(6):760-766, 2020

253. Choi G, Modi HN, Prada N, Ahn TJ, Myung SH, Gang MS, et al.: Clinical results of XMR-assisted percutaneous transforaminal endoscopic lumbar discectomy. J Orthop Surg Res 8(1): 1-8, 2013

254. Fan G, Wang T, Hu S, Guan X, Gu X, He S: Isocentric navigation of percutaneous endoscopic transforaminal discectomy at the L5/S1 level in difficult puncture cases: A technical note. Pain Physician 20(4):E531-540, 2017 